\title{
Prehabilitation for adults diagnosed with cancer: A systematic review of long-term physical function, nutrition and patient-reported outcomes
}

\author{
Sara Faithfull ${ }^{1}$ (i) | Lauren Turner ${ }^{2}$ | Karen Poole ${ }^{1}$ | Mark Joy ${ }^{1}$ | Ralph Manders ${ }^{3}$ | \\ Jennifer Weprin ${ }^{4}$ | Kerri Winters-Stone ${ }^{4}$ John Saxton ${ }^{5}$
}

${ }^{1}$ School of Health Sciences, Faculty of Health \& Medical Sciences, University of Surrey, Guildford, UK

${ }^{2}$ Frimley Health NHS Foundation Trust, Frimley, Surrey, UK

${ }^{3}$ Exercise Physiology and Sports Science, University Surrey, Guildford, UK

${ }^{4}$ School of Nursing, Knight Cancer Institute, Oregon Health \& Science University, Portland, Oregon

${ }^{5}$ Department of Sport Exercise and Rehabilitation, Northumbria University, Newcastle Upon Tyne, UK

Correspondence

Sara Faithfull, School of Health Sciences, Faculty of Health and Medical Sciences, University of Surrey, Guildford, UK.

Email: s.faithfull@surrey.ac.uk

\begin{abstract}
Objective: Prehabilitation is increasingly being used to mitigate treatment-related complications and enhance recovery. An individual's state of health at diagnosis, including obesity, physical fitness and comorbidities, are influencing factors for the occurrence of adverse effects. This review explores whether prehabilitation works in improving health outcomes at or beyond the initial 30 days post-treatment and considers the utility of prehabilitation before cancer treatment.

Methods: A database search was conducted for articles published with prehabilitation as a pre-cancer treatment intervention between 2009 and 2017. Studies with no 30 days post-treatment data were excluded. Outcomes post-prehabilitation were extracted for physical function, nutrition and patient-reported outcomes.

Results: Sixteen randomised controlled trials with a combined 2017 participants and six observational studies with 289 participants were included. Prehabilitation interventions provided multi-modality components including exercise, nutrition and psychoeducational aspects. Prehabilitation improved gait, cardiopulmonary function, urinary continence, lung function and mood 30 days post-treatment but was not consistent across studies. Conclusion: When combined with rehabilitation, greater benefits were seen in 30 day gait and physical functioning compared to prehabilitation alone. Large-scale randomised studies are required to translate what is already known from feasibility studies to improve overall health and increase long-term cancer patient outcomes.

KEYWORDS

cancer, exercise, nutrition, prehabilitation, rehabilitation, survivorship
\end{abstract}

\section{1 | INTRODUCTION}

Prehabilitation offers a route to improving patient's physical status and buffering treatment-related deconditioning between the time of cancer diagnosis and post-treatment recovery. Prehabilitation includes physical and psychological assessments that establish baseline functioning and identify impairments that can impact on cancer treatment-related morbidity, as well as providing targeted interventions to maximise patient function prior to treatment onset (Silver \& Baima, 2013). The primary goal of prehabilitation is "to prevent

This article is published with the permission of the Controller of HMSO and the Queen's Printer for Scotland. 
or reduce the severity of anticipated treatment-related impairments that may cause significant disability (page2)" (Silver \& Baima, 2013). There are several systematic reviews of prehabilitation for those receiving cancer surgery (Boereboom, Doleman, Lund, \& Williams, 2016; Carli et al., 2017; Singh, Netwon, Galvao, Spry, \& Baker, 2013), and all suggest that prehabilitation enhances early discharge from hospital and reduces surgical adverse effects. There is a growing requirement to include prehabil itation as part of the cancer pathway with three recent reports advising the value of prehabilitation, two in the USA (National Academies of Sciences, 2018; Stout et al., 2016) and one in the UK (Macmillan Cancer Support, 2018). However, evidence that prehabilitation translates into better long-term patient outcomes beyond the initial 30 days post-treatment complications is lacking.

Challenges to providing prehabilitation are that cancer patients are highly likely to have comorbidities that complicate treatment delivery and reduce physical fitness (Sarfati, Koczwara, \& Jackson, 2016; Stairmand et al., 2015). Comorbid conditions associated with ageing and particularly excess body weight are common in patients presenting with cancer (Goodwin \& Chlebowski, 2016), and evidence from epidemiological studies suggests that comorbidities and poorer health are correlates of poorer survival (Land, Dalton, Jensen, \& Ewertz 2012a, 2012b). There is compelling evidence for the link between obesity and cancer outcomes (Calle, Rodriguez, Walker-Thurmond, \& Thun, 2003) with particular associations in the following tumour sites; breast (Jiralerspong \& Goodwin, 2016), gastrointestinal (Brown \& Meyerhardt, 2016), endometrial (Onstad, Schmandt, \& Lu, 2016), prostate (Vidal et al., 2014) and haematological cancers, including multiple myeloma and leukaemia (Yang, Drake, \& Colditz, 2016). Obesity is an important risk factor for cardiovascular, kidney disease, diabetes and some musculoskeletal disorders (2016). These obesity-related comorbidities contribute to the adverse effects of cancer treatment (Bradley, Dahman, Fau-Anscher, \& Anscher, 2014; Søgaard, Thomsen, Bossen, Sørensen, \& Nørgaard, 2013) and combined with an ageing demographic, where more than $60 \%$ of cancer patients are over 65 , comorbidity and poorer physical and functional health will impact upon future cancer treatment delivery and outcomes (Greenlee, Shi, Molmenti, Rundle, \& Tsai, 2016). These coexisting health problems are strong indicators for providing prehabilitation to maximise cancer treatment outcomes.

Rehabilitation interventions such as exercise, weight reduction and pharmacotherapy are recognised ways of managing comorbidity-related conditions after cancer treatment (Alamuddin, Bakizada, \& Wadden, 2016), and there is evidence that smoking cessation (Sitas et al., 2014) reduces adverse treatment effects and improves survival. Preparing patients prior to cancer therapy by improving their overall health status as in prehabilitation could optimise their response to treatment and has important implications for future service delivery (Silver \& Baima, 2013). Prehabilitation has been espoused as a key component of early recovery in cancer patients and is a term that has been traditionally used to describe interventions for optimising cardiopulmonary reserve prior to cancer surgery, with the aim of improving post-operative recovery outcomes (Carli et al., 2017; Silver, 2015; Silver \& Baima, 2013). However, prehabilitation programmes are also targeting this pre-treatment period to improve chemotherapy adherence (Le Roy et al., 2016), reduce anxiety (Tsimopoulou et al., 2015) and to provide a stronger platform for post-treatment rehabilitation aimed at reversing treatment-related side effects and symptoms, managing comorbidities and enhancing longer-term health-related quality of life (Alfano, Ganz, Rowland, \& Hahn, 2012; Boereboom, Williams, Leighton, \& Lund, 2015; Shun, 2016; Silver, 2014). While fewer studies have been undertaken outside of the surgical context, a growing number of studies are focusing on different cancer treatments and modes of prehabilitation using exercise, psychological support and nutritional interventions. These studies need to look at longer-term outcomes beyond the traditional enhanced recovery 30 days post-treatment outcomes, to understand treatment adherence, mortality, disease prognosis or impact on health economics (Stout et al., 2018). This is the first systematic review to critically review the impact of different prehabilitation interventions on long-term health outcomes (at or beyond 30 days post-treatment completion) in cancer patients and explore the utility of prehabilitation as a platform for risk management before and after all cancer treatments.

This review addressed two questions:

1. What is the effect of prehabilitation on $\geq 30$ days post-treatment outcomes including physical functioning, nutrition and patientreported outcomes?

2. How can prehabilitation be used to optimise the management of cancer patients with comorbidity or pre-existing risk factors that are associated with poorer cancer treatment outcomes?

\section{2 | METHODS}

\subsection{Data Sources and search method}

The review was registered on PROSPERO (CRD42016050296) international prospective database of systematic reviews. The search was conducted in two stages. In stage one, studies were identified via abstracts through a systematic search strategy for Medline (Pub med), CINAHL (with full text) EMBASE and Cochrane central register of controlled trials. The databases were chosen to identify potentially relevant published studies in the field of medicine, exercise, health and psychosocial care. Search terms were split into two categories "prehabilitation combined with cancer" and terms to identify the nature of prehabilitation such as "exercise, nutrition, psychology and other behavioural interventions," The full search strategy and MESH terms are provided in supplementary materials. In stage two, other relevant publications were retrieved by reviewing the reference lists of these studies against the eligibility criteria.

Studies selected were published from the period 2000 to February 2017. The following were all excluded from the review: prehabilitation studies with no reported post-treatment outcomes at 30 days or longer; studies that combined data from previously published studies; and abstracts, case studies, conference abstracts and 
those not in English. Participants included were cancer patients who were treated with any treatment modality and received any form of prehabilitation either in the home or hospital setting. Prehabilitation was defined as a single- or multi-modality intervention that could include exercise, nutritional support, patient education and/or psychological therapy. Control was defined as those participant's receiving usual care as defined in the clinical pathway. Identification of objective clinical, patient-reported and delivery outcomes was described at 30 days post-treatment completion. Comorbidity data at baseline and at completion were also reviewed. Efficacy in relation to 30 days post-treatment objective physical functioning was explored through meta-analysis but data were not of sufficient quality to make a

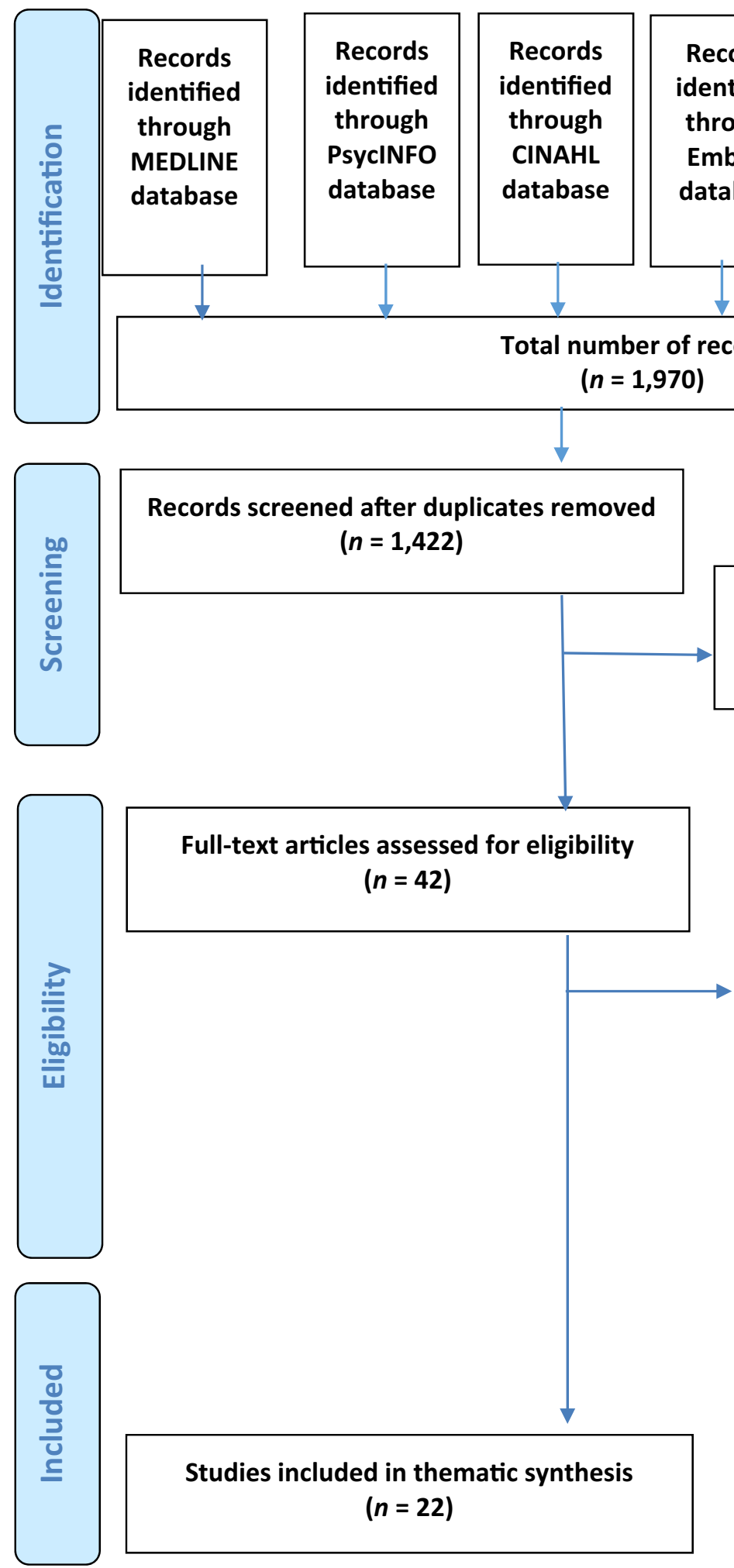

Full-text articles excluded, with reasons $(n=20)$ 1.Not prehabilitation

2.Not reporting on outcomes more than 30 days from treatment);

3. Case study

4. Not reporting on cancer treatment

FIGURE 1 PRISMA study selection flow chart 


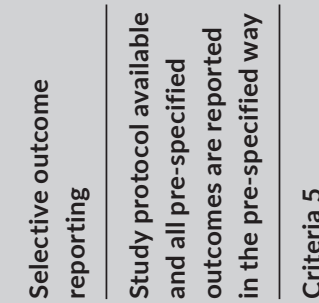

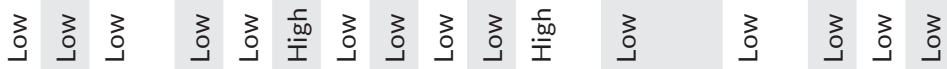

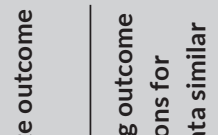

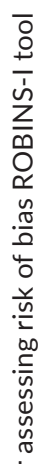

$\frac{\pi}{\circ}$

욤

흔

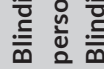
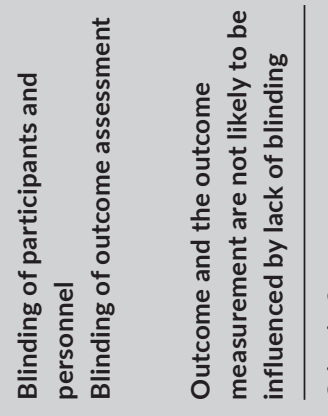

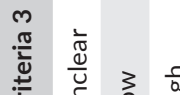

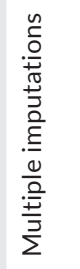

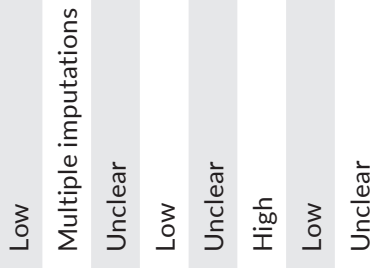

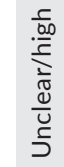

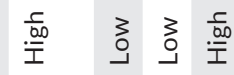

$\frac{0}{\frac{0}{0}}$

ن
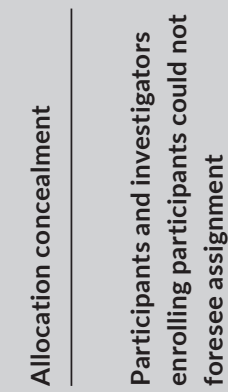

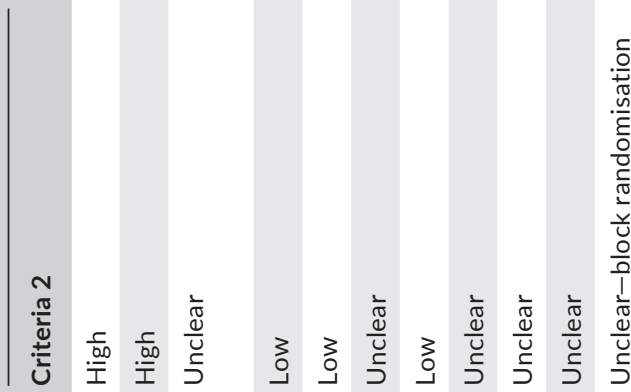

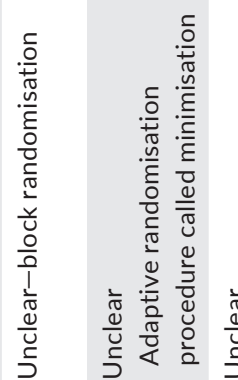

离

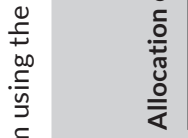

产竞
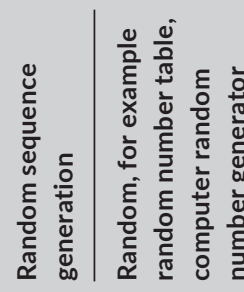

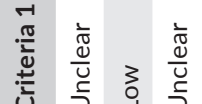

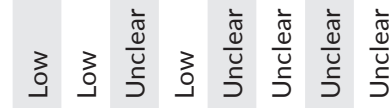

$\frac{\frac{1}{\pi}}{\frac{\pi}{5}}$

$3 \quad 3 \quad 3 \quad \frac{\frac{1}{\pi}}{5}$

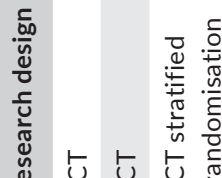

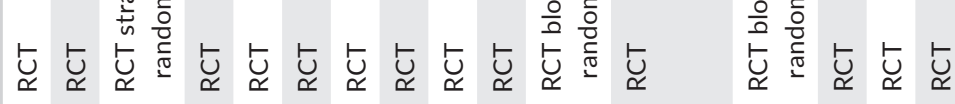

$\sum^{\pi}$

$\frac{-6}{\frac{\pi}{2}}$

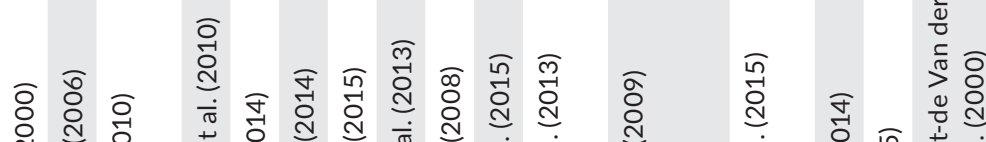

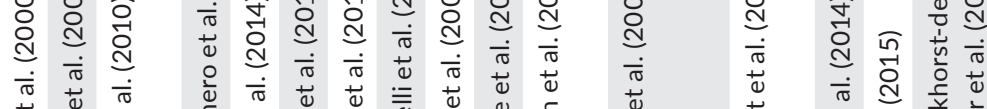


comparison. The quality of eligible studies was assessed using the PRISMA critical appraisal methods (Shamseer L et al., 2015). Risk of bias was assessed by an interdisciplinary research team using the Cochrane Collaboration's tool for assessing risk of bias ROBINS-I tool (Sterne et al., 2016). Observational or quasi-experimental studies were included as they provided additional information as to the use of prehabilitation interventions.

\section{3 | RESULTS}

Sixteen randomised controlled trials (RCT) and six observational studies were included in the narrative synthesis (Figure 1). The quality of the RCT studies varied considerably with 7 of the 16 studies being considered as having a high risk of bias. Studies were not sufficiently consistent in intervention or outcome data to be included in a meta-analysis. In many studies reporting of the randomisation processes, lack of allocation concealment to those enrolling, blinding of outcome assessors and poor reporting of missing data may have impacted on study quality (Table 1). Most studies were single-centre studies. However, one of two multi-site studies was a three-arm trial comparing psychological prehabilitation strategies, with participants randomised to stress management, a support group or usual care (Parker et al., 2009). Other studies compared different prehabilitation components head to head as nutritional interventions or psychological approaches. The number of participants within the RCTs ranged from 48 to 652 , with a median of 88 with a total number of subjects in the review of 2017 (Table 1). Most individual RCTs analysed fewer than $60 \%$ of the sample originally recruited in the study, excluding participants due to comorbidity or inability to undergo cardiopulmonary exercise testing. Participants were adults with colorectal (Carli et al., 2010; Cheville et al., 2015; Gillis et al., ; Moriya, 2015) lung (Barlési et al., 2008; Stefanelli et al., 2013), head and neck (Van Bokhorst-de Van der Schuer et al., 2000), breast (Garssen et al., 2013), bladder (Jensen, Krintel Petersen, Jensen, Lausten, \& Borre, 2014; Jensen, Petersen, Jensen, Laustsen, \& Borre, 2015) and prostate (Bales et al., 2000; Burgio et al., 2006; Parker et al., 2009) cancer or included individuals with a range of cancers (Schmidt et al., 2015). Trial designs were primarily feasibility studies, and therefore, the studies were rarely powered to determine the efficacy of prehabilitation on post-treatment recovery outcomes. The primary endpoint was predominantly objective physical function prior to treatment with the secondary endpoints described at 1-6 months post-intervention. Only four (25\%) of the authors fully reported participant comorbidities at baseline (Burgio et al., 2006; Jensen et al., 2015; Schmidt et al., 2015; Van Bokhorst-de Van der Schuer et al., 2000) while two actively excluded participants with comorbidities possibly due to the intensity of the exercise programme (Carli et al., 2010; Stefanelli et al., 2013).

The designs of the six observational studies were either casecontrolled cohort, historical controls or quasi-experimental. Studies were primarily feasibility studies, and participant numbers were small, ranging from 35 to 87 with a total of 289 participants. Studies included individuals with breast cancer (Baima et al., 2015), lung cancer (Jones et al., 2007; Peddle et al., 2009; Sekine et al., 2005), colorectal cancer (Li et al., 2013) and prostate cancer (Sueppel, Kreder, \& See, 2001).

Comorbidities were only reported in three of the studies at baseline, with ill health being cited as a contributing factor to difficulties with recruitment rather than this being recorded as an outcome. Several studies did not report attrition (Sekine et al., 2005; Sueppel et al., 2001), and among those that did attrition rates ranged from $0 \%$ to $52 \%$. The number and combination of prehabilitation modalities varied considerably across studies, ranging from 1 to 3 across individual RCTs and observational studies (Tables 2 and 3).

Most (16/22) studies included an exercise modality, either as a stand-alone prehabilitation intervention or in combination. Four studies examined the effects of pelvic floor training in men with prostate cancer over a varying number of weeks before radical prostatectomy (Bales et al., 2000; Burgio et al., 2006; Centemero et al., 2010; Sueppel et al., 2001). These were predominantly home-based exercise programmes with some level of instruction and supervision and/or biofeedback training. Two studies incorporated supervised therapeutic pulmonary exercises (in conjunction with more conventional conditioning exercise) in lung cancer patients in the 2-3 weeks prior to surgery (Sekine et al., 2005; Stefanelli et al., 2013). These exercises were performed on 5-7 days per week and included incentive spirometry, abdominal breathing, huffing and coughing, and respiratory exercises on a bench, mattress pad and wall bars. Finally, a study in breast cancer patients investigated the feasibility of therapeutic shoulder mobility exercises in the 2-4 weeks before surgery, comparing in-person teaching with video-only teaching (Baima et al., 2015). Both methods were shown to be feasible with high adherence ( $\geq 75 \%)$. Other studies investigated the effects of conventional forms of exercise conditioning for improving cardiopulmonary fitness and/or muscular strength over durations of 2-8 weeks, though most programmes were of 2- to 4-week duration (Tables 2 and 3 ). All but one of these studies implemented exercise prehabilitation in the time period before colorectal, lung or bladder cancer surgery, whereas the remaining study (Cheville et al., 2015) focused on adherence to chemoradiotherapy in patients with gastrointestinal cancers. Home-based programmes generally consisted of aerobic and resistance exercise on at least three days per week with varying degrees of face-to-face supervision and telephone support (Carli et al., 2010; Gillis et al., 2014; Jensen et al., ; Li et al., 2013). Instructions on both the frequency and intensity of aerobic exercise were generally provided, and in some cases, participants used heart rate monitors and perceived exertion scales to self-assess their level of effort (Gillis et al., 2014; Li et al., 2013). Studies of more closely supervised 2- to 6-week programmes of exercise prehabilitation involved vigorous intensity cycle ergometry in lung (Jones et al., 2007; Peddle et al., 2009) and rectal cancer patients (West et al., 2015) prior to surgery and isokinetic muscle strengthening exercises in patients with gastrointestinal cancers during chemoradiotherapy (Cheville et al., 2015). Two further studies included vigorous gym-based aerobic exercise (Stefanelli et al., 2013) or walking exercise (5,000 steps/ 

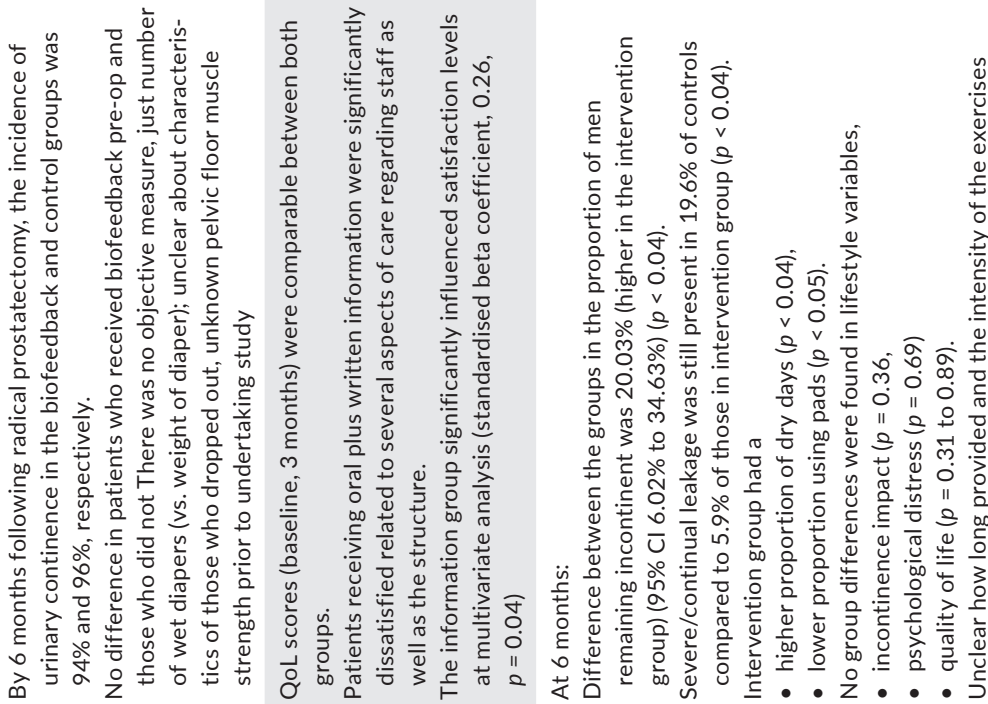

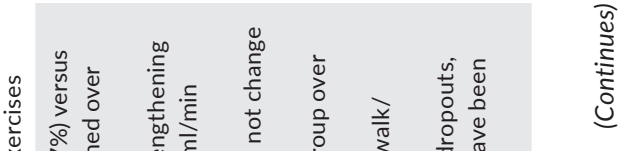
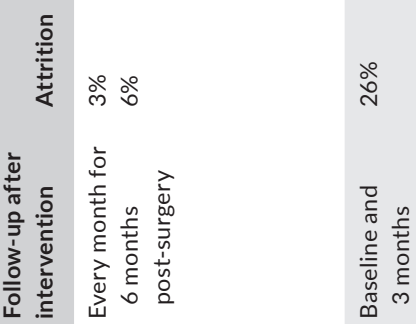

ळे

১̊ำ
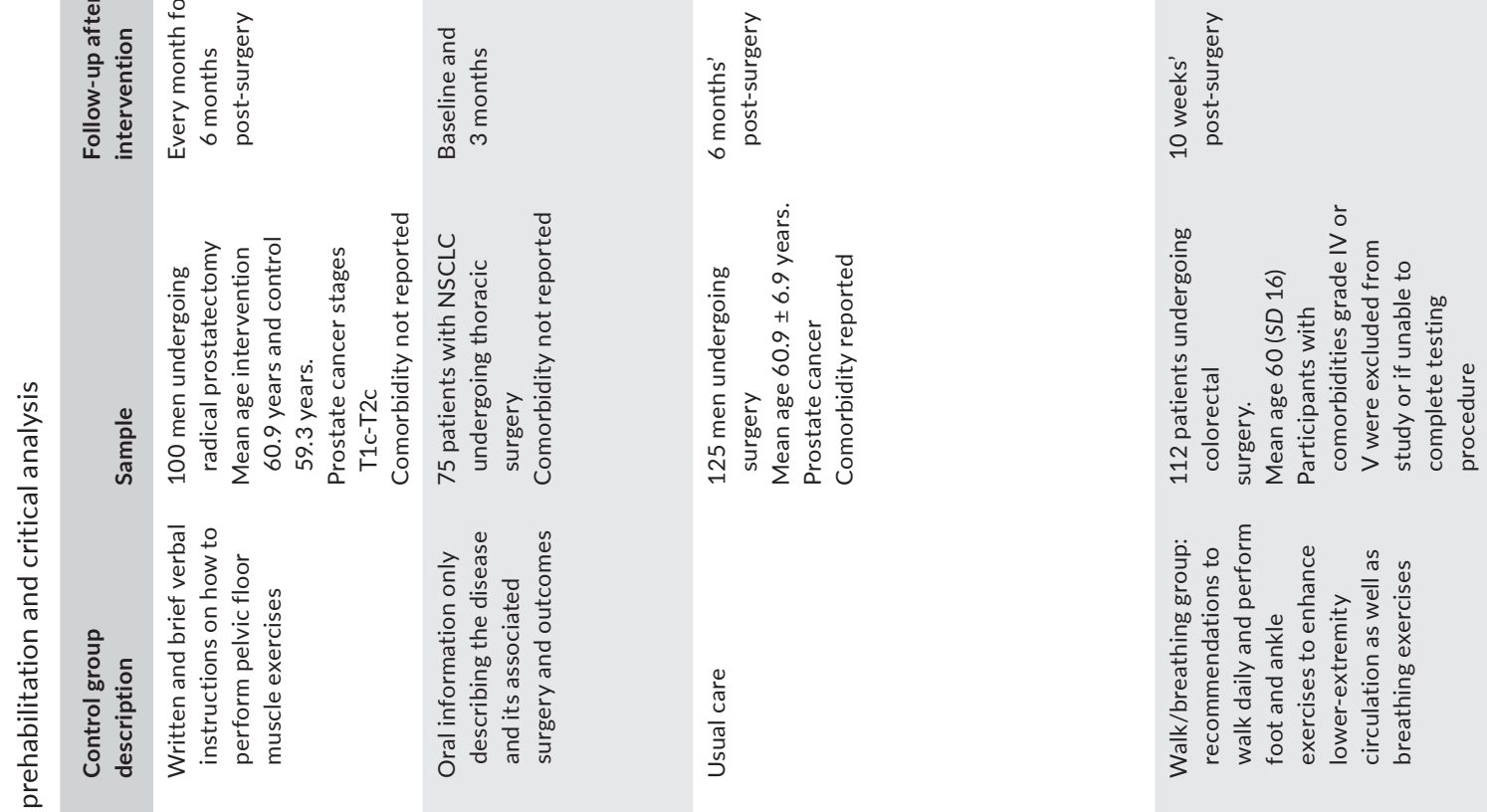

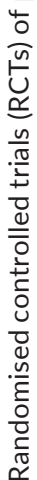

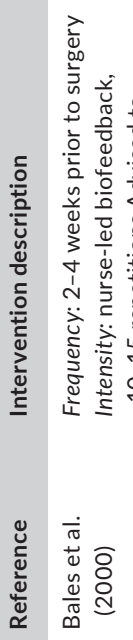<smiles>C1CCCCC1</smiles>
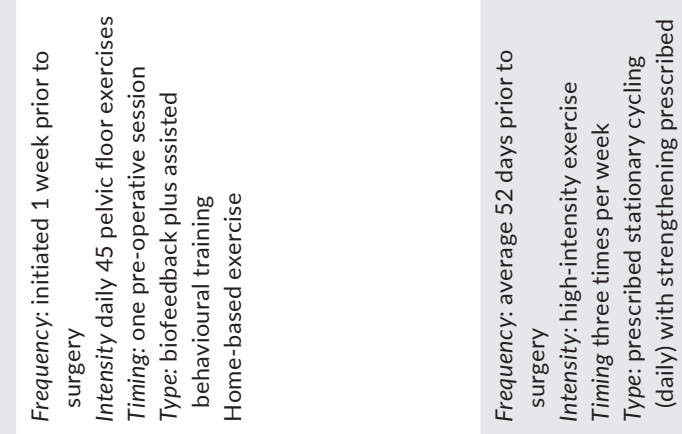

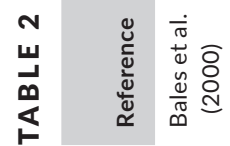
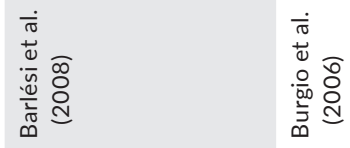

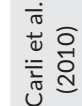




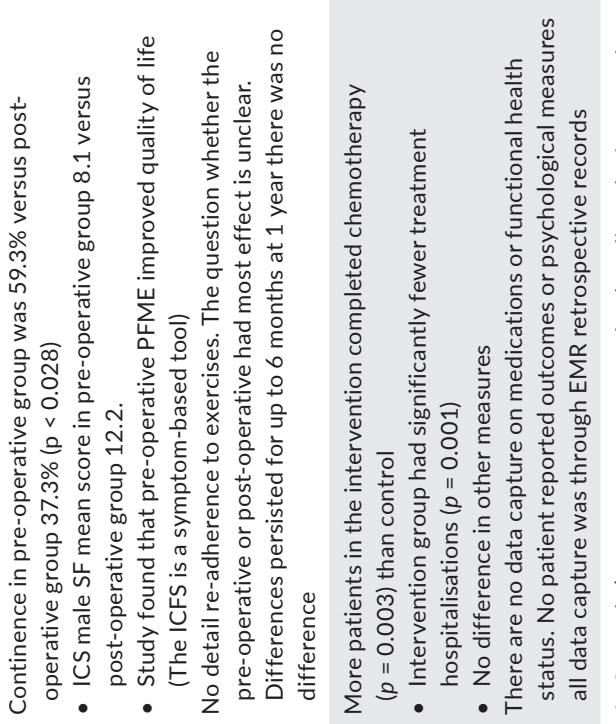

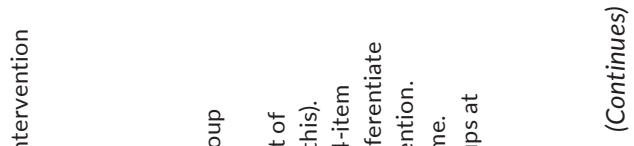

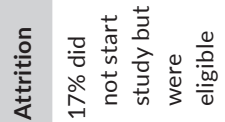

苍

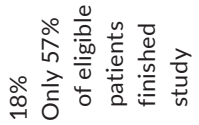

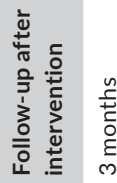

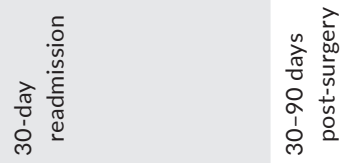
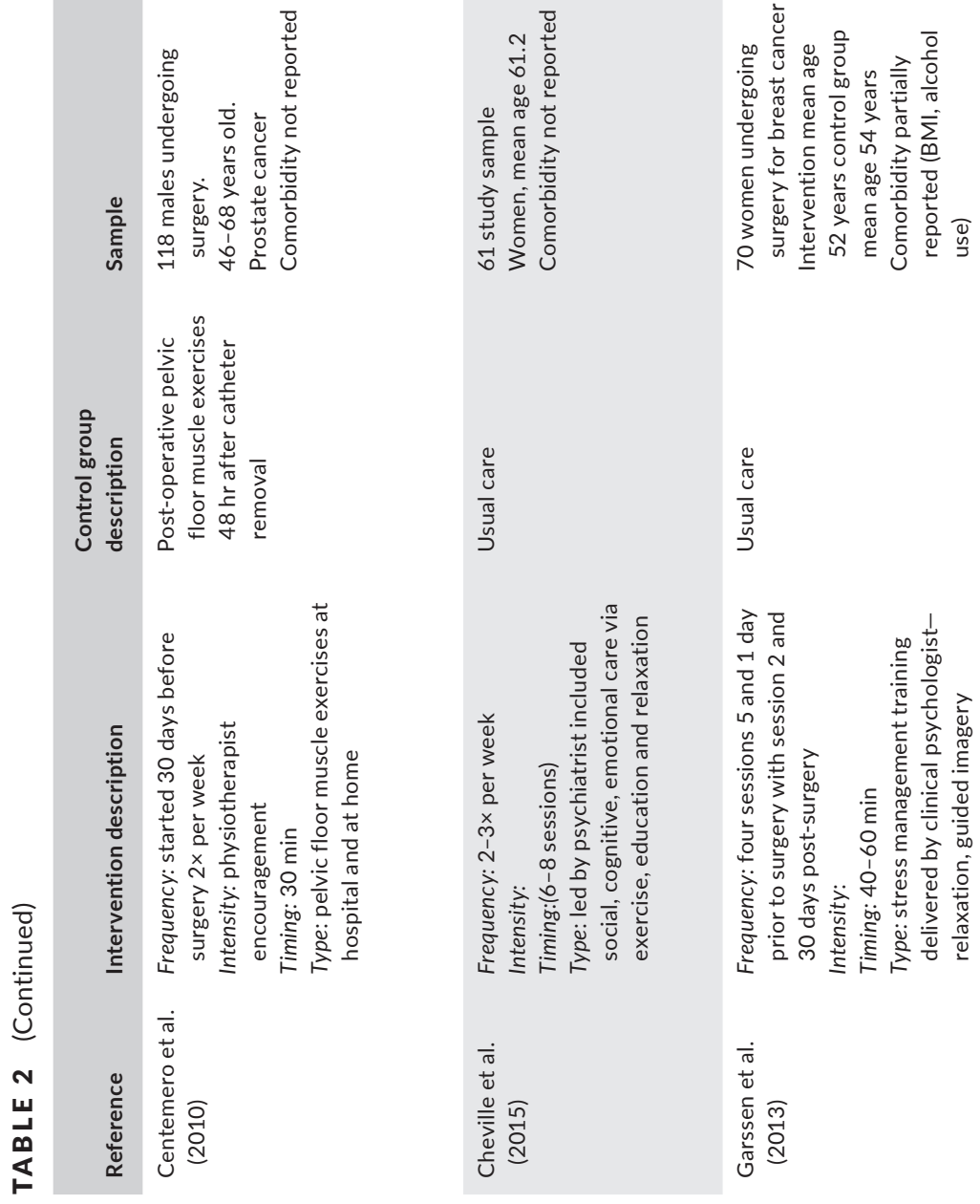

$\frac{\sqrt{2}}{\frac{\pi}{\frac{\pi}{2}}}$

$\frac{\sqrt{2}}{\frac{\pi}{3}}$

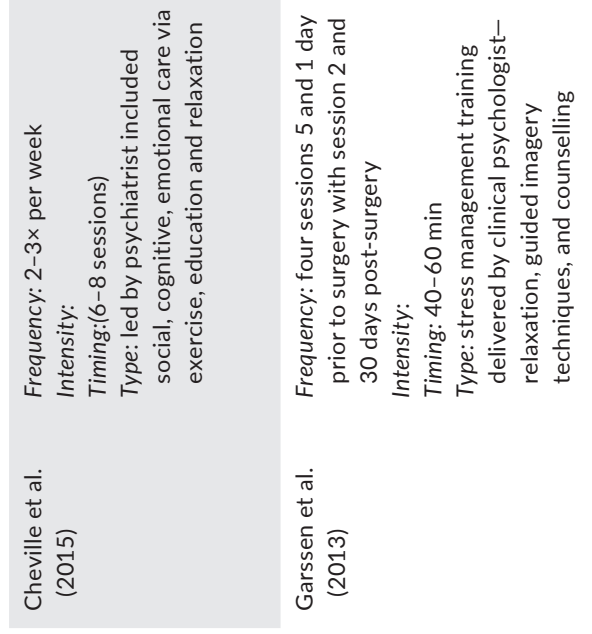




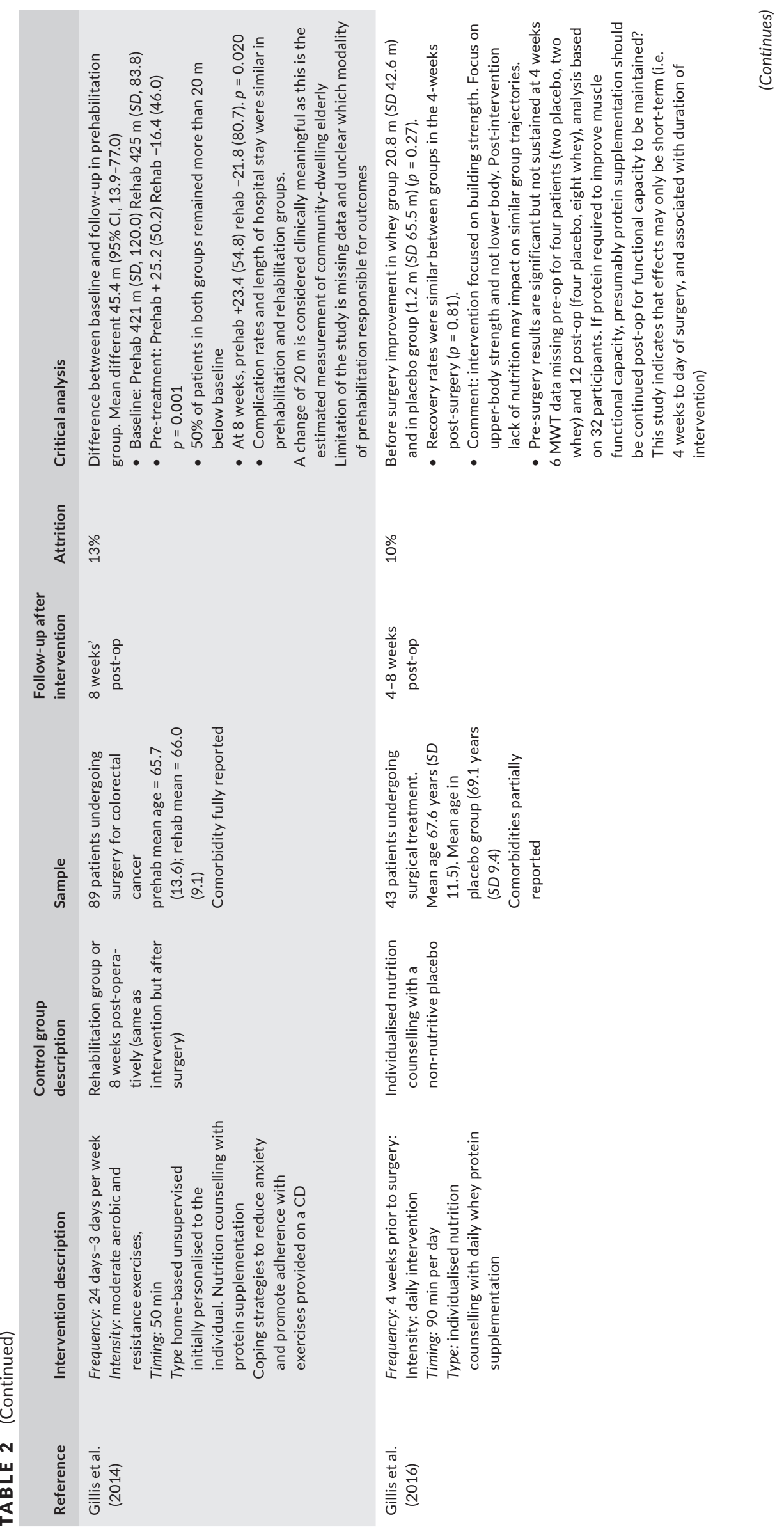




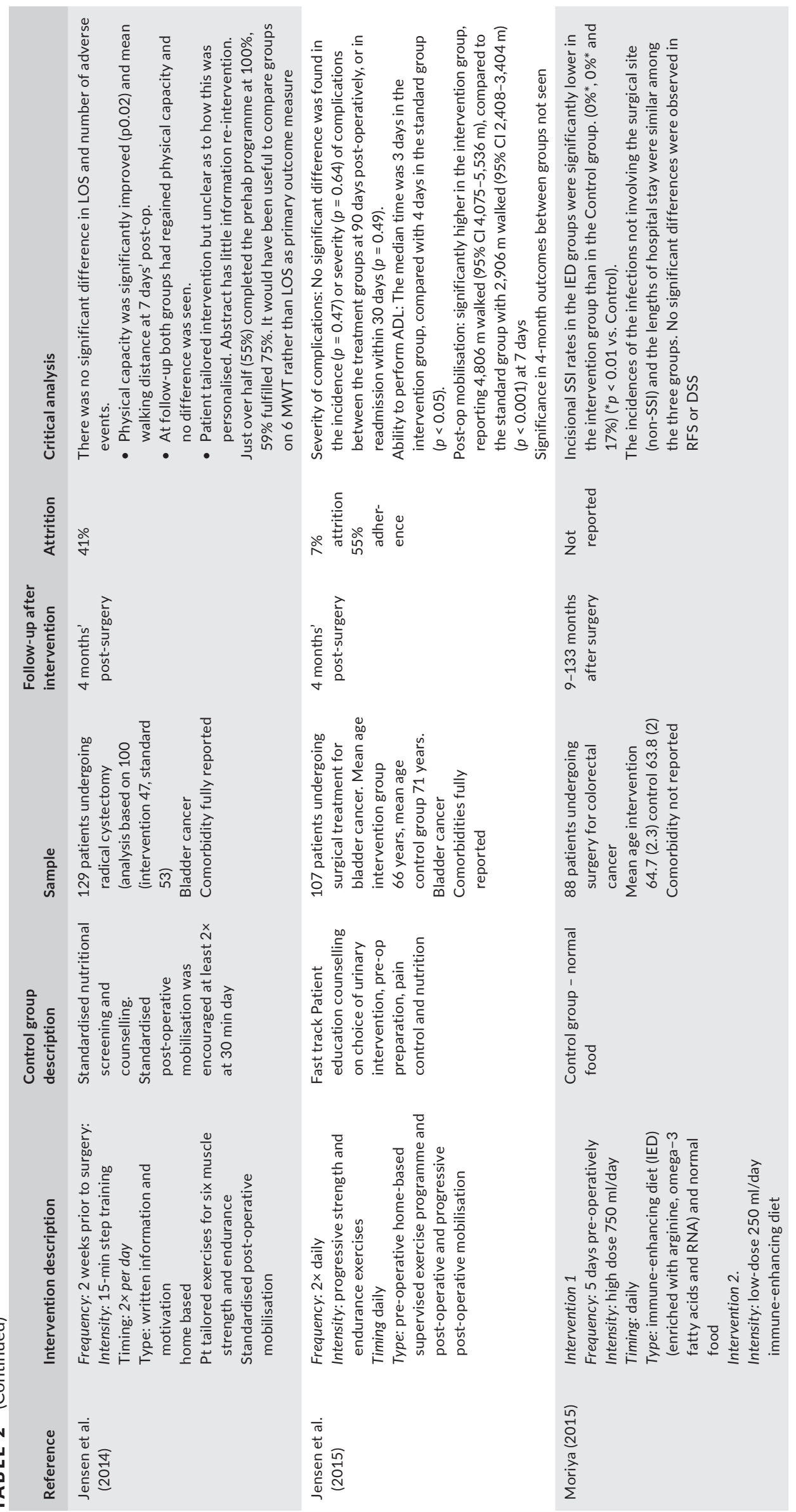




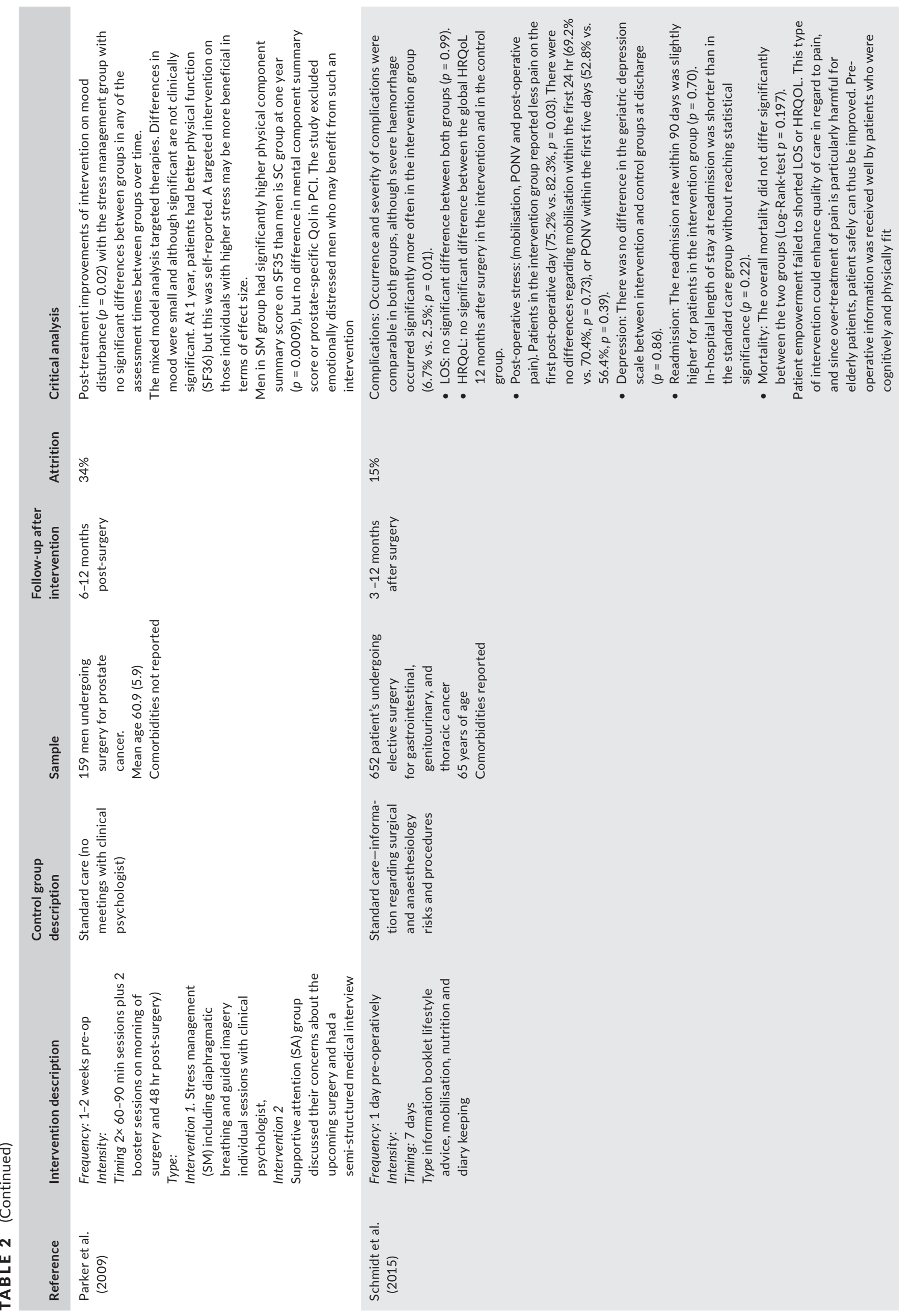




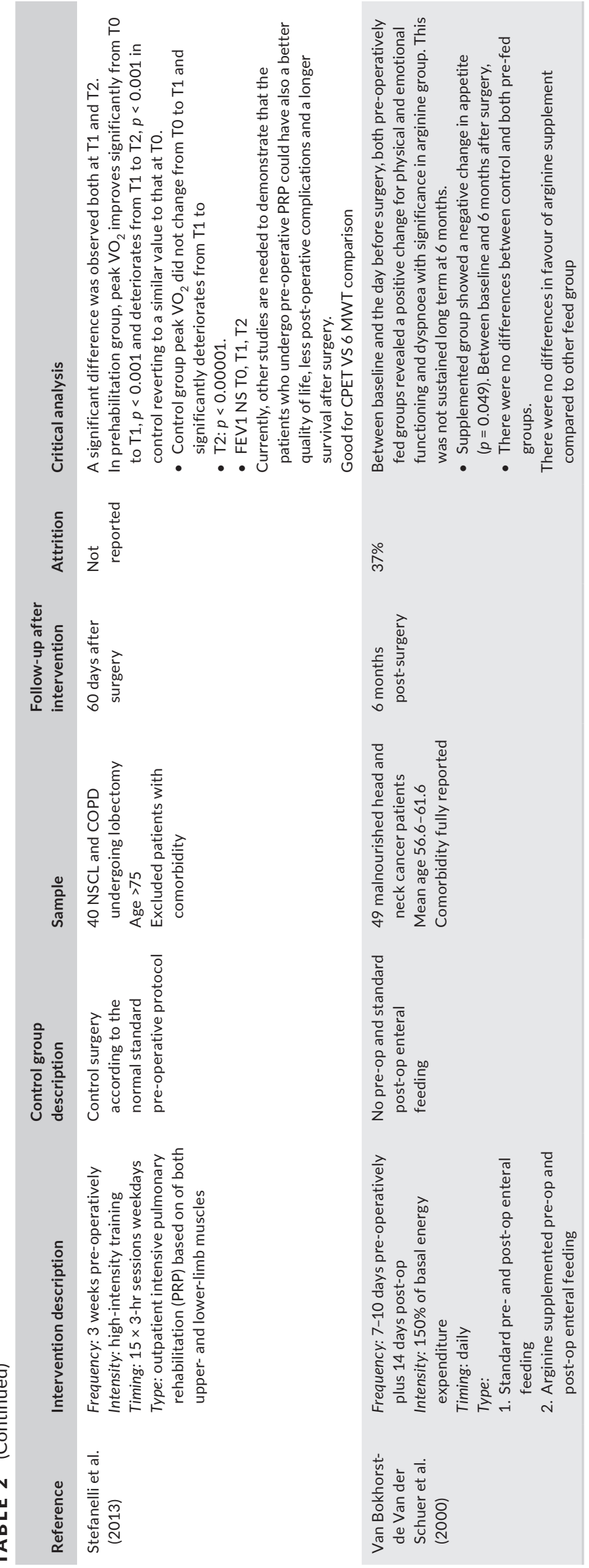



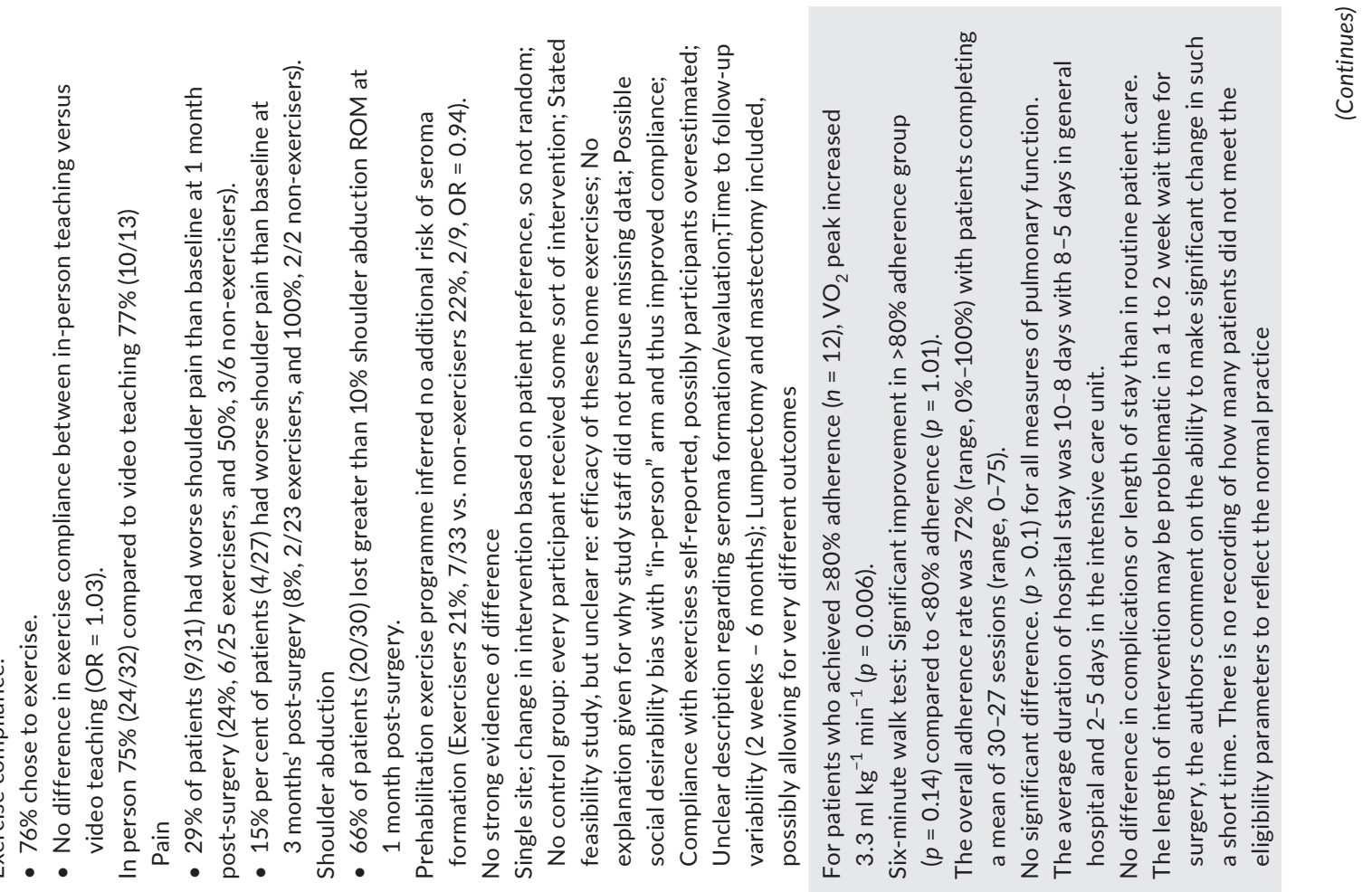

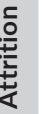

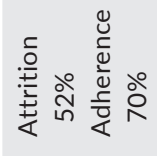

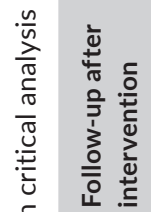

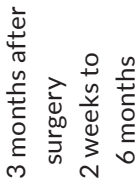

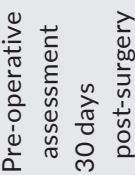

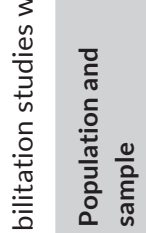

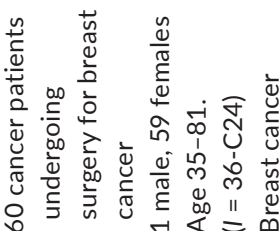

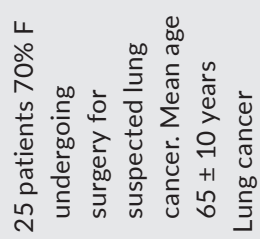

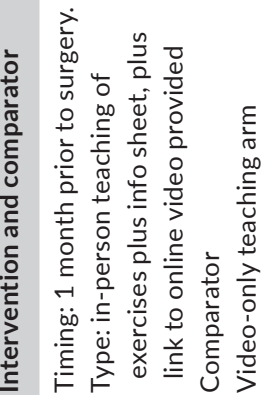

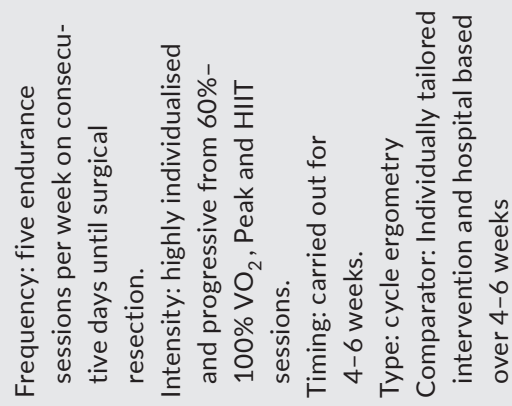

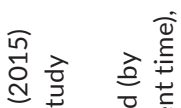

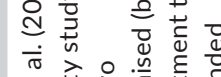

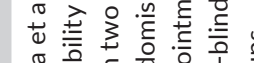

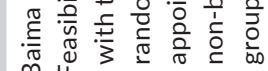

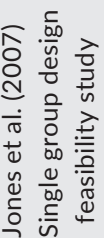



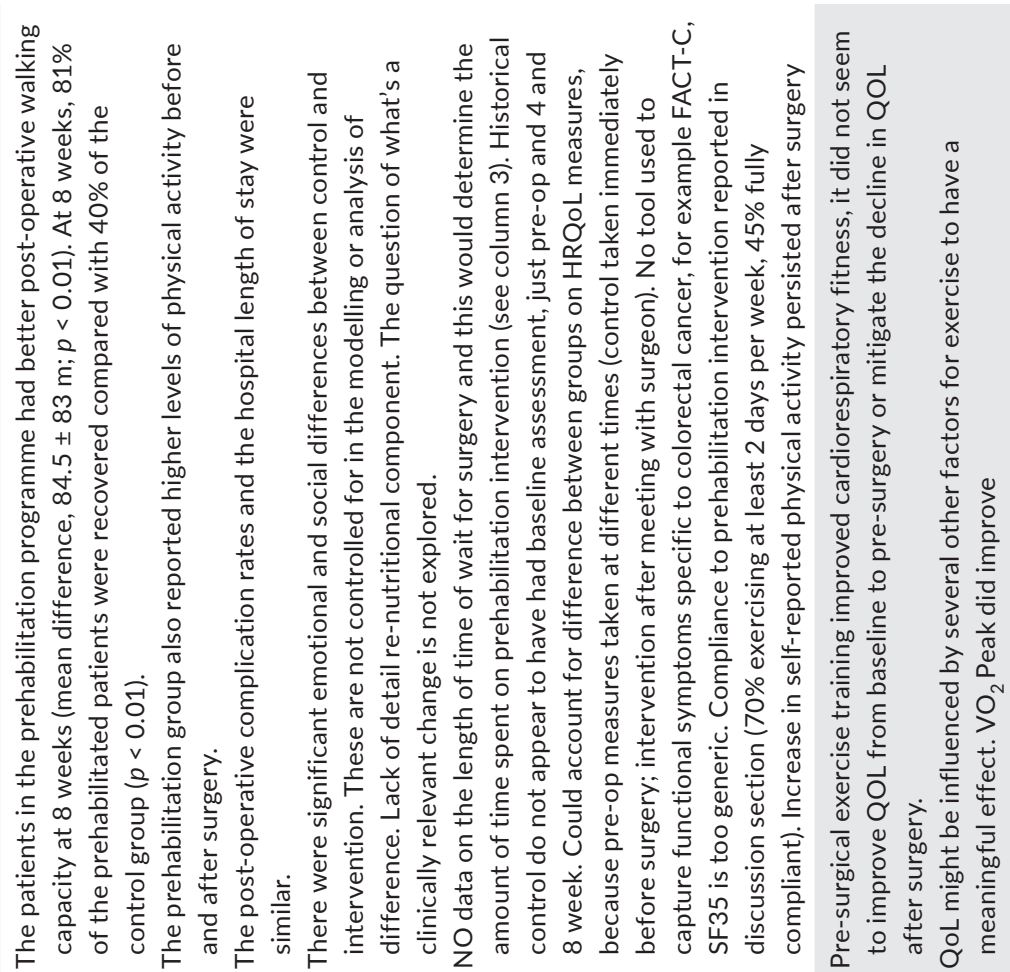

旁

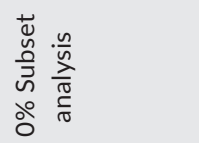

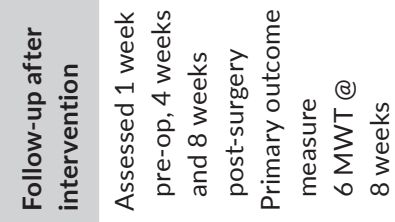

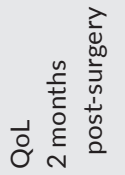

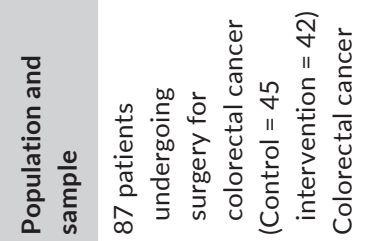
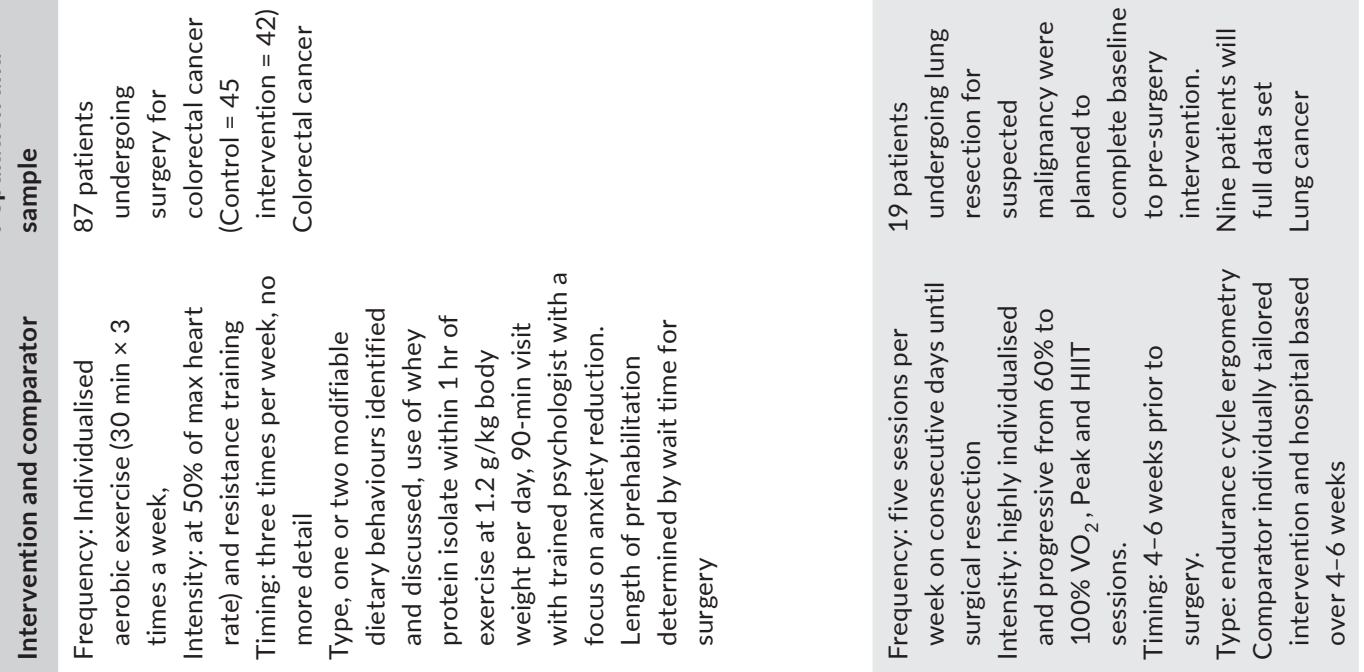

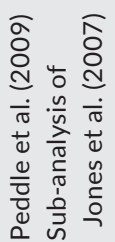




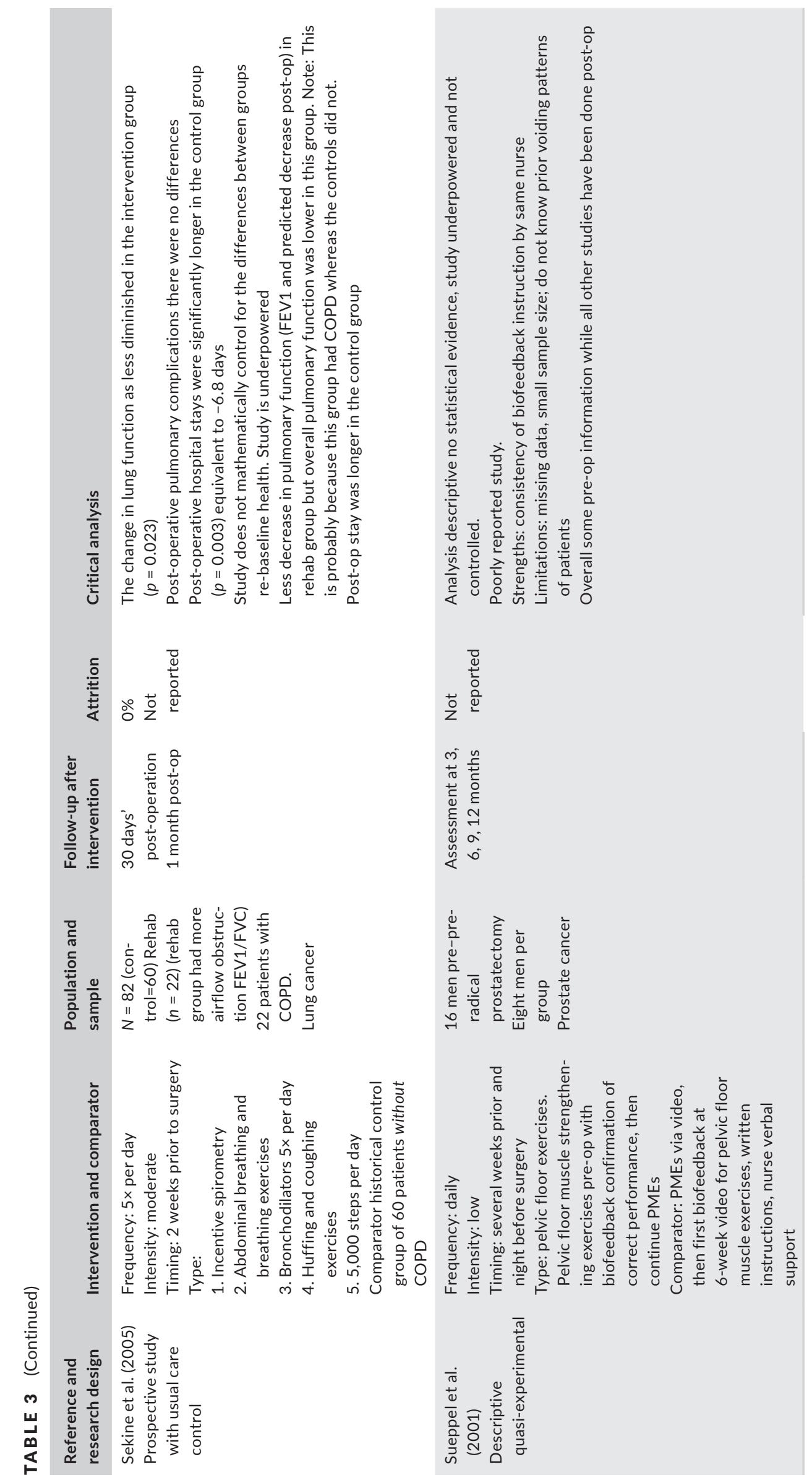


day) (Sekine et al., 2005) in combination with therapeutic pulmonary exercises in patients with lung cancer prior to surgery. The short timelines prior to therapy made a progressive programme difficult to achieve. Although adherence to the home exercise programme was reported in most of these studies, adherence to exercise at the prescribed intensity and progression of the exercise programme were poorly reported.

Only five of the studies provided a nutritional modality as part of the prehabilitation package. Some of the interventions were purely nutrition based (Gillis et al., 2016; Moriya, 2015; Van Bokhorst-de Van der Schuer et al., 2000); however, two of the studies used nutrition as part of multi-component prehabilitation intervention (Gillis et al., 2016; Li et al., 2013). The nutritional interventions were varied with 5-10 days pre-operative feeding plus a supplemental arginine formula (Van Bokhorst-de Van der Schuer et al., 2000) or whey protein (Gillis et al., 2014; Li et al., 2013) or a low or high dose immune-enhancing diet (Moriya, 2015). Multi-modal prehabilitation interventions provided 90 min of nutritional counselling with daily whey protein supplementation (Gillis et al., 2016) in comparison with a control group which received nutritional counselling without supplementation. The timing of nutritional interventions varied between 5-10 days (Gillis et al., 2016; Moriya, 2015) and 3-6 weeks pre-operatively (Gillis et al., 2014; Li et al., 2013). The nutritional intervention did not continue beyond surgery, with one exception (Gillis et al., 2016) which continued the nutritional intervention 4 weeks' postsurgery. Nutritional therapies were primarily targeted on individuals with cancer who were malnourished, receiving treatment for head and neck (Van Bokhorst-de Van der Schuer et al., 2000) or colorectal cancer (Gillis et al., ; Li et al., 2013; Moriya, 2015). Van Bokhorstde Van der Schuer et al. (2000) excluded adults from the study if they were well nourished (10\% excluded), whereas Gillis et al. (2016) screened for malnutrition using the Patient Generated-Subjective Global Assessment (PG-SGA) which is a validated tool for nutritional assessment in oncology. Adherence to nutritional intervention is reported in only one study with researchers contacting participants on a weekly basis to encourage them to record their whey protein ingestion. This study noted that adherence was higher in the prehabilitation group compared to the rehabilitation group both pre- and post-surgery.

Studies involving a psychoeducation modality as part of prehabilitation programmes have focused primarily on anxiety and stress reduction(Cheville et al., 2015; Garssen et al., 2013; Parker et al., 2009; Schmidt et al., 2015), patient education and lifestyle advice (Baima et al., 2015; Barlési et al., 2008) (Jensen et al., 2015) and/ or counselling (Parker et al., 2009) as part of the intervention; however, few studies report any detail of the therapeutic components of the intervention. Psychoeducational prehabilitation strategies have been studied as single mode counselling interventions (Barlési et al., 2008; Cheville et al., 2015) or by comparing a variety of psychological and educational approaches prior to cancer treatment (Parker et al., 2009). Psychoeducational strategies have also been studied as part of multi-component prehabilitation programmes (Gillis et al., 2014; Jensen et al., ). Psychoeducational interventions prior to surgery for lung and gastrointestinal cancer provided written and verbal information to participants which described the disease and associated surgery outcomes (Barlési et al., 2008; Schmidt et al., 2015). An alternative psychotherapeutic approach involved weekly group sessions with a psychiatrist, focused on individuals' social, cognitive and emotional care in conjunction with relaxation exercises 30 days prior to chemotherapy(Cheville et al., 2015). Similarly, Garsen (Garssen et al., 2013) provided 4 sessions over 5 days to women with breast cancer, including stress management, relaxation, guided imagery techniques and counselling. Parker et al. (2009) investigated the effects of a similar programme on post-operative recovery outcomes in men with prostate cancer. These interventions were all compared to usual or supportive care. Adherence to the intervention was not always reported in the observational studies with attrition $25 \%-52 \%$ respectively (Baima et al., 2015) (Jones et al., 2007).

\section{1 | Objective clinical outcomes following prehabilitation}

Studies that included an exercise modality investigated the effects of prehabilitation regimens on cancer treatment recovery outcomes and cardiopulmonary fitness (Table 4). Three studies reported favourable effects of home-based pelvic floor training on post-operative urinary continence outcomes in prostate cancer patients undergoing radical prostatectomy up to 12 months of follow-up (Burgio et al., 2006; Centemero et al., 2010; Sueppel et al., 2001), and a fourth study (Bales et al., 2000) showed no urinary continence benefits of including biofeedback training. Similarly, a study of female breast cancer patients reported no additional postoperative benefits when home-based shoulder exercise prehabilitation included an in-person teaching session versus video-based instruction (Baima et al., 2015). Supervised exercise prehabilitation programmes in lung cancer patients have generally been more intensive than home-based programmes and have resulted in improvements in pre-operative cardiopulmonary fitness measures, including six-minute walk test (6 MWT) (Jones et al., 2007) and peak $\mathrm{VO}_{2}$ (Jones et al., 2007; Stefanelli et al., 2013). However, the improvements in peak $\mathrm{VO}_{2}$ were modest $\left(2-3 \mathrm{ml} \mathrm{kg}^{-1} \mathrm{~min}^{-1}\right)$ and it is unclear whether improvements of this magnitude translate to improved post-operative recovery outcomes or longer-term outcomes, such as quality of life. It is of interest to note that intensive cycle ergometry prehabilitation had no impact on quality of life pre-surgery or at 2 months post-surgery (Peddle et al., 2009). Nevertheless, Sekine et al. (2005) reported a reduction in post-operative pulmonary complications and hospital length of stay in lung cancer patients after a prehabilitation programme that involved daily pulmonary therapeutic exercises and walking $(5,000$ steps/day) in the two weeks prior to lobectomy when compared to historical controls. In other studies, prehabilitation programmes involving exercise have yielded equivocal results. A supervised programme involving cycling + strengthening exercises in patients with gastrointestinal cancer compared to those in a walking + breathing exercise group showed no differences in 


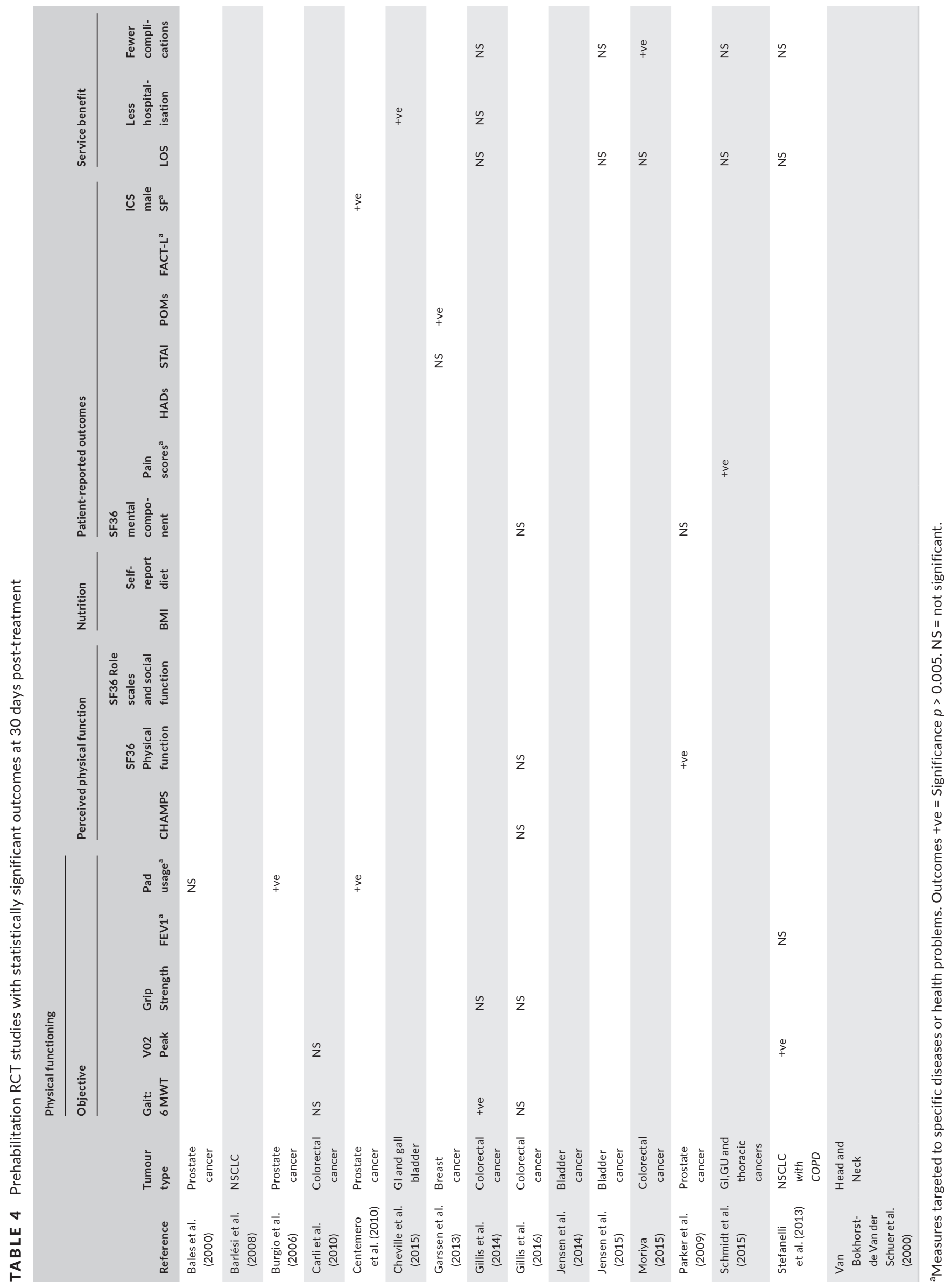




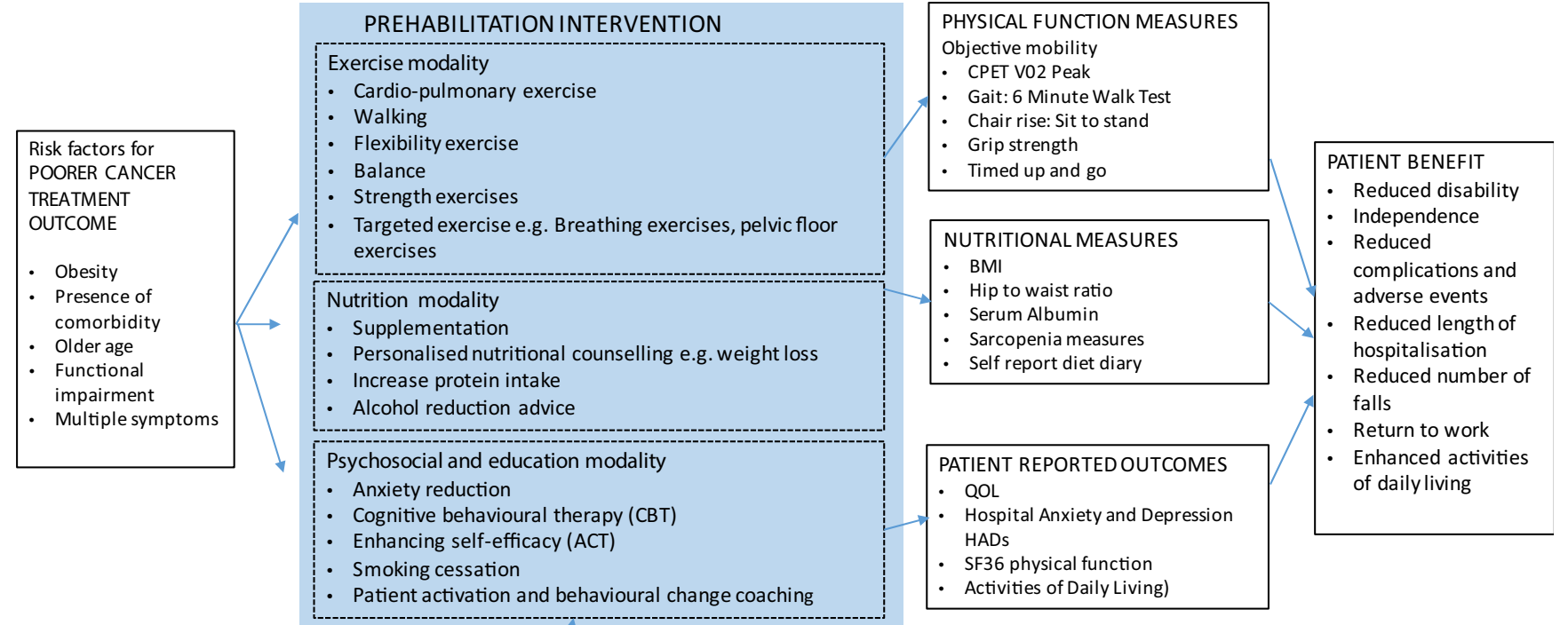

PROCESS measures of Prehabilitation

Participation from population and adherence

Frequency, intensity, timing and type of prehabilitation intervention

Safety considerations (e.g. restrictions, adverse events)

FIGURE 2 Summary of multi-modality prehabilitation outcomes and measurement

6 MWT distance (Carli et al., 2010). Similarly, home-based exercise programmes involving aerobic and/or resistance exercise 4 weeks prior to surgery have had minimal impact on post-operative hospital length of stay or severity of complication (Gillis et al., 2014; Jensen et al., ), although Jensen et al. (2015) reported improved post-operative 6 MWT distance in bladder cancer patients receiving prehabilitation, $4,806 \mathrm{~m}(95 \% \mathrm{Cl} 4,075-5,536 \mathrm{~m})$ compared to $2,906 \mathrm{~m}(95 \% \mathrm{Cl} 2,408-3,404 \mathrm{~m})$ in those receiving usual care. Gillis (Gillis et al., 2014) reported higher submaximal cardiopulmonary fitness $+23.4 \mathrm{~m}$ (6 MWT) in a prehabilitation/rehabilitation group compared to rehabilitation alone $-21.8 \mathrm{~m}$ (80.7) at 8 weeks after colorectal cancer surgery.

Studies that included nutritional outcomes were few and reported no significant differences between the intervention and control groups at $\geq 30$ days (Moriya, 2015) on post-treatment physical functioning (Table 4). However, pre-operative nutritional modality groups showed a significant improvement in physical functioning and initial symptoms post-operatively (Gillis et al., 2014; Li et al., 2013; Van Bokhorst-de Van der Schuer et al., 2000). Only one study measured upper-body strength (Gillis et al., 2016), and this improved pre-surgery but was not sustained post-surgery. Participants who received arginine supplementation with feeding pre- and post-surgery showed reduced appetite at 6 months (Van Bokhorst-de Van der Schuer et al., 2000), and serum albumin remained stable in a small $(n=17)$ pre-post-intervention study ( $\mathrm{Li}$ et al., 2013). However, prehabilitation studies' nutritional outcomes are compromised by the lack of consistency in measuring nutritional intake and adherence (mainly through self-report tools) or objective sarcopenia measures. Such limitations could have important implications for assessing treatment fidelity and the sensitivity of outcome measures.

\section{2 | Patient-reported outcomes (PRO) of prehabilitation}

PRO in the studies reviewed included health-related quality of life using the Short Form Health Survey (SF36) and Prostate Cancer Index (PCI), which incorporate physical and emotional subscales. Symptom specific measures such as the International Continence Scale for men (ICS male), the Hospital Anxiety and Depression Scale (HADs) and ( $\mathrm{PCl}$ ) and Activities of Daily Living (ADL) tool were also reported in some studies (Table 4). Quality of life scores were comparable between prehabilitation and control groups at 3 months post-intervention in most studies (Barlési et al., 2008; Burgio et al., 2006; Garssen et al., 2013; Peddle et al., 2009). However, in two studies, self-reported physical function was higher in the prehabilitation group at 1 year (Li et al., 2013; Parker et al., 2009), and in the study by Li et al. (2013), an increase in self-reported physical activity persisted 8 weeks after surgery. Post-treatment improvements in mood, anxiety and depression have been reported immediately post-operatively following prehabilitation involving walking + breathing exercises and psychological support (Carli et al., 2010; Parker et al., 2009; Schmidt et al., 2015) but effects were small and between-group differences were not sustained long-term (Parker et al., 2009; Schmidt et al., 2015). Behavioural change techniques, such as smoking cessation, were rarely reported in studies; this can impact on radiotherapy side effects and subsequent post-treatment cancer outcomes (Warren, Sobus, \& Gritz, 2014). 


\section{3 | Patient-reported and service outcomes for prehabilitation}

Complication rates and length of hospital stay (LOS) post-surgery were the most frequent service delivery measures reported for $\geq 30$ days post-treatment (Table 4). There was no difference in length of stay, between prehabilitation and control groups in five studies (Gillis et al., ; Jensen et al., 2014; Li et al., 2013; Schmidt et al., 2015), with the exception of Sekines (Sekine et al., 2005), where the intervention group had a reduced length of stay after a 4- to 6-week prehabilitation programme. Post-operative complications such as wound healing, seroma formation and bleeding were shown to be comparable between intervention and control groups but Moriya (Moriya, 2015) found that those receiving a prehabilitation nutritional intervention had fewer post-operative site infections. Prehabilitation has been shown to improve initial post-operative mobilisation (Jensen et al., 2015) and the number of patients completing chemotherapy (Cheville et al., 2015). Furthermore, in the latter study, those receiving the intervention had significantly fewer treatment hospitalisations.

\section{DISCUSSION}

Overall, this systematic review suggests prehabilitation impacts on select 30-day outcome measures for some people with cancer but few studies have measured or reported overall long-term health benefits. The results of the review are summarised pictorially as a diagram describing the multi-modality intervention and linked physical function, nutrition and patient-reported outcomes used in the reviewed studies (Figure 2). Many of these studies report service or process data measures such as length of stay and post-operative complications, but do not consistently capture changes in physical functioning or patient-reported outcomes. The only exception is pre-operative therapeutic pelvic floor exercises for men undergoing prostatectomy for prostate cancer where prehabilitation improved long-term urinary continence. This reflects the differentiation between general prehabilitation versus targeted exercise or nutrition interventions and the greater specificity of their effect. There is insufficient evidence for demonstration of long-term benefits in other cancer patient populations beyond the initial 30 days post-treatment complications. Even vigorous intensity pre-operative aerobic exercise conditioning programmes have only resulted in modest improvements in peak oxygen uptake pre-operatively (of the order of $2-3 \mathrm{ml} \mathrm{kg}^{-1} \mathrm{~min}^{-1}$ ), possibly a factor of the short duration of programmes, and these gains are lost post-operatively. Not surprisingly then, prehabilitation combined with rehabilitation was the most effective approach in improving outcomes longer than 30 days.

It is now recognised that a physically active lifestyle is inversely related to the risk of certain cancers and mortality (Brown, Winters-Stone, Lee, \& Schmitz, 2012; Schmid \& Leitzmann, 2014). Surprisingly few prehabilitation studies measured or reported participant comorbidities and how they changed over time. Therefore, we were unable to address our second question, how prehabilitation can optimise the management of cancer patients with comorbidity? Comorbidities in participants in prehabilitation studies were considered exclusion criteria rather than as predictors of physical functioning that could be mediated by exercise or nutrition and that could change as a response to intervention (Brown et al., 2012). Those participants with high levels of comorbidities and poor fitness were often not eligible to be included, which suggests those people most in need to improve physical function were less likely to receive prehabilitation. The multi-modality approach of prehabilitation could optimise the management of cancer patients with low baseline scores and who have been shown to gain greater benefits (Minnella et al., 2016). Rather than trying to demonstrate the efficacy of multi-modality prehabilitation on the fittest patients, we should consider using the approach to optimise the management of the more complex and least fit cancer patients who have most to gain. This requires more sophisticated tailoring of intervention to personalise and target prehabilitation. For example, current exercise guidelines for cancer survivors recommend muscle strengthening exercises for overall conditioning (Schmitz et al., 2010) but this may not be sufficient to manage specific deficits. A more task-specific approach incorporating functional movements using strength and mobility may be optimal for prehabilitation regimens (WintersStone et al., 2015).

In some studies, the high attrition of participants suggests a balance is required between intensity and duration of exercise to be able to meet the needs of those with greater limitations. This highlights the need for continuity and support in establishing exercise habits and expectations around exercise for people with cancer (Brown et al., 2012; Mayo et al., 2011). The content of exercise programmes is poorly described in some papers and has not followed the FITT principle of reporting Frequency, Intensity, Timing and Type of exercise and/or how the exercise programme is personalised or progressed over time (Thompson, Gordon, \& Pescatello, 2010). These oversights make it challenging to understand whether or not the exercise programme was insufficiently designed and/or how to revise programmes to optimise adherence and outcomes in the future.

The inclusion of nutritional support as part of prehabilitation improved short-term physical function. The pre-surgical interventions were necessarily short (2-3 weeks) primarily due to treatment target times. Indications from one study suggest that longer-term patient outcomes could benefit with additional post-surgical rehabilitation. Given the rising proportion of cancer patients who are obese at diagnosis, the prehabilitive window and rehabilitative window are potentially an opportunity to embed new lifestyle behaviours. Malnutrition is associated with a poorer response to cancer treatment, and hypoalbuminaemia is associated with postsurgical mortality, increased morbidity and length of stay (Hu et al., 2015). Patients with colorectal cancer are more malnourished than other patients groups ( $28 \%$ colorectal compared to $4 \%$ prostate cancer) (Hu et al., 2015) hence the wide number of prehabilitation studies in this population. In the nutrition components of 
prehabilitation programmes, surrogate measures were used for the combined interventions rather than specific targets such as serum values or anthropometric measures. If we are tackling obesity in cancer and its risks, then a greater focus on adiposity, fat distribution and sarcopenia should be included in prehabilitation studies. With emerging therapies and earlier diagnosis techniques, for example of low dose computerised imaging in lung cancer (Smith, Khanna, \& Wisotzky, 2017), the opportunity for prehabilitation becomes more feasible as patients are less likely to be burdened by advanced disease or chronic illness.

Understanding how prehabilitation components work together is a challenge as few studies used a theoretical or conceptual frameworks to guide design. Exploring how the multi-modality components work, such as exercise, nutrition, psychoeducational components, is essential to maximise outcomes (Figure 2). The use of factorial research designs in future studies is recommended in evaluating prehabilitation components (Montgomery, Peters, \& Little, 2003). While pre-operative exercise programmes have incorporated both aerobic and resistance training, most emphasis has been on aerobic exercise. The effect of resistance exercise on pre-operative muscular function and how this impacts upon post-operative recovery outcomes has received less attention (Singh et al., 2013). The relationship between psychological health and exercise behaviour has been well established. Short- and long-term adherence may be optimised if anxiety and depression are also addressed during an exercise programme; however, the focus on anxiety and depression management at the expense of evidence-based behaviour change strategies may not be the best strategy for long-term adherence (Stacey, James, Chapman, Courneya, \& Lubans, 2015).

A limitation of this review is that conclusions have to be considered in the context of a limited number of studies, the majority of which are underpowered feasibility studies. The importance of feasibility studies is recognised in the Medical Research Council (MRC) complex intervention framework and that they should now be used to inform fully powered RCTs. The review highlighted the need for improved quality of studies, for example following consort or strobe reporting guidance, and this has also been described in previous prehabilitation systematic reviews (Singh et al., 2013). It is imperative that future studies take a more ambitious approach to test efficacy by building on the current evidence base using a conceptual framework to guide intervention design and robust evaluation.

Can prehabilitation programmes impact on longer-term cancer health outcomes? The answer is currently unclear especially in relation to changing comorbidity. Prehabilitation is now an integral part of many cancer surgical preparatory pathways as part of early recovery but there is scope for greater targeting to include nutrition and psychoeducational components, as well as considering how prehabilitative interventions may buffer symptoms such as fatigue and pain during adjuvant therapies. Sophisticated research designs incorporating economic evaluation and longer-term measures are essential to guide service development and support implementation if the concept of cancer prehabilitation is to emulate cardiac rehabilitation services.
In conclusion, prehabilitation strategies may have an important role to play in addressing the rising complexity of health needs of those diagnosed with cancer. Forty per cent of all those diagnosed with cancer have one comorbid condition and $15 \%$ at least two concurrent health problems (Sarfati et al., 2016). This systematic review highlights that single- and multi-modal prehabilitation programmes are feasible and some approaches confer short-term benefits in the post-surgical recovery period. The next stage is to design robust efficacy studies to test carefully defined prehabilitative/prehabilitative-rehabilitative interventions at the time of first cancer treatment (be that surgery, systemic anti-cancer therapy or radiotherapy) and measure clinical outcome, PRO, patient benefit and service delivery outcomes throughout the care pathway.

\section{CONFLICTS OF INTEREST}

The authors have no conflicts of interest to report.

\section{AUTHORS CONTRIBUTION}

All authors have made a substantive contribution to the publication: S Faithfull, L Turner and K Poole developed the protocol and contributed to the review, analysis and writing. R Manders, J Weprin and $M$ Joy contributed to the analysis and $K$ Winters-Stone and $J$ Saxton assisted with drafting the publication. All authors approved the final version.

\section{ORCID}

Sara Faithfull (iD https://orcid.org/0000-0002-7951-0243

\section{REFERENCES}

Alamuddin, N., Bakizada, Z., \& Wadden, T. A. (2016). Management of obesity. Journal of Clinical Oncology, 34(35), 4295-4305. https://doi. org/10.1200/jco.2016.66.8806

Alfano, C. M., Ganz, P. A., Rowland, J. H., \& Hahn, E. E. (2012). Cancer survivorship and cancer rehabilitation: Revitalizing the link. Journal of Clinical Oncology, 30(9), 904-906. https://doi.org/10.1200/jco.2011.37.1674

Baima, J., Reynolds, S. G., Edmiston, K., Larkin, A., Ward, B. M., \& O'Connor, A. (2015). Teaching of independent exercises for prehabilitation in breast cancer. Journal of Cancer Education, 32, 252-256. https://doi. org/10.1007/s13187-015-0940-y

Bales, G. T., Gerber, G. S., Minor, T. X., Mhoon, D. A., McFarland, J. M., Kim, H. L., \& Brendler, C. B. (2000). Effect of preoperative biofeedback/pelvic floor training on continence in men undergoing radical prostatectomy. Urology, 56, 627-630. https://doi.org/10.1016/ s0090-4295(00)00687-7

Barlési, F., Barrau, K., Loundou, A., Doddoli, C., Simeoni, M. C., Auquier, P., \& Thomas, P. (2008). Impact of information on quality of life and satisfaction of non-small cell lung cancer patients: A randomized study of standardized versus individualized information before thoracic surgery. Journal of Thoracic Oncology, 3(10), 1146-1152. https:// doi.org/10.1097/jto.0b013e3181874637

Boereboom, C., Doleman, B., Lund, J., \& Williams, J. (2016). Systematic review of pre-operative exercise in colorectal cancer patients. Techniques in Coloproctology, 20, 81-89. https://doi.org/10.1007/ s10151-015-1407-1 
Boereboom, C. L., Williams, J. P., Leighton, P., Lund, J. N., \& Exercise Prehabilitation in Colorectal Cancer Delphi Study, G. (2015). Forming a consensus opinion on exercise prehabilitation in elderly colorectal cancer patients: A Delphi study. Techniques in Coloproctology, 19(6), 347-354. https://doi.org/10.1007/s10151-015-1317-2

Bradley, C. J., Dahman, B., Fau-Anscher, M., \& Anscher, M. (2014). Prostate cancer treatment and survival: Evidence for men with prevalent comorbid conditions. Medical Care 52, 482-489 (1537-1948 (Electronic)). https://doi.org/10.1097/MLR.0000000000000113

Brown, J. C., \& Meyerhardt, J. A. (2016). Obesity and energy balance in GI cancer. Journal of Clinical Oncology, 34(35), 4217-4224. https:// doi.org/10.1200/JCO.2016.66.8699

Brown, J. C., Winters-Stone, K., Lee, A., \& Schmitz, K. H. (2012). Cancer, physical activity, and exercise. Comprehensive Physiology, 2(4), 27752809. https://doi.org/10.1002/cphy.c120005

Burgio, K. L., Goode, P. S., Urban, D. A., Umlauf, M. G., Locher, J. L., Bueschen, A., \& Redden, D. T. (2006). Preoperative biofeedback assisted behavioral training to decrease post-prostatectomy incontinence: a randomized, controlled trial. Journal of Urology 175(1), 196-201; discussion 201.

Calle, E. E., Rodriguez, C., Walker-Thurmond, K., \& Thun, M. J. (2003). Overweight, obesity, and mortality from cancer in a prospectively studied cohort of U.S. Adults. New England Journal of Medicine, 348(17), 1625-1638. https://doi.org/10.1056/nejmoa021423

Carli, F., Charlebois, P., Stein, B., Feldman, L., Zavorsky, G., Kim, D. J., ... Mayo, N. E. (2010). Randomized clinical trial of prehabilitation in colorectal surgery. British Journal of Surgery, 97(8), 1187-1197. https:// doi.org/10.1002/bjs.7102

Carli, F., Silver, J. K., Feldman, L. S., McKee, A., Gilman, S., Gillis, C., ... Hirsch, B. (2017). Surgical prehabilitation in patients with cancer: State-of-the-science and recommendations for future research from a panel of subject matter experts. Physical Medicine and Rehabilitation Clinics of North America, 28(1), 49-64. https://doi.org/10.1016/j. pmr.2016.09.002

Centemero, A., Rigatti, L., Giraudo, D., Lazzeri, M., Lughezzani, G., Zugna, D., ... Guazzoni, G. (2010). Preoperative pelvic floor muscle exercise for early continence after radical prostatectomy: A randomised controlled study. European Urology, 57(6), 1039-1043. https://doi. org/10.1016/j.eururo.2010.02.028

Cheville, A. L., Alberts, S. R., Rummans, T. A., Basford, J. R., Lapid, M. I. Sloan, J. A., ... Clark, M. M. (2015). Improving adherence to cancer treatment by addressing quality of life in patients with advanced gastrointestinal cancers. Journal of Pain and Symptom Management, 50(3), 321-327. https://doi.org/10.1016/j.jpainsymman.2015.03.005

Collaboration, N. C. D. R. F. (2016). Trends in adult body-mass index in 200 countries from 1975 to 2014: A pooled analysis of 1698 population-based measurement studies with $19 \cdot 2$ million participants. The Lancet, 387(10026), 1377-1396. https://doi.org/10.1016/ S0140-6736(16)30054-X

Garssen, B., Boomsma, M. F., Meezenbroek, E. e. J., Porsild, T., Berkhof, J., Berbee, M., ... Beelen, R. H. (2013). Stress management training for breast cancer surgery patients. Psychooncology, 22(3), 572-580. https://doi.org/10.1002/pon.3034

Gillis, C., Li, C., Lee, L., Awasthi, R., Augustin, B., Gamsa, A., ... Carli, F. (2014). Prehabilitation versus rehabilitation: A randomized control trial in patients undergoing colorectal resection for cancer. Anesthesiology, 121(5), 937-947. https://doi.org/10.1097/ ALN.0000000000000393

Gillis, C., Loiselle, S. E., Fiore, J. F. Jr, Awasthi, R., Wykes, L., Liberman, A. S., ... Carli, F. (2016). Prehabilitation with whey protein supplementation on perioperative functional exercise capacity in patients undergoing colorectal resection for cancer: A pilot double-blinded randomized placebo-controlled trial. Journal of the Academy of Nutrition and Dietetics, 116(5), 802-812. https://doi.org/10.1016/j. jand.2015.06.007
Goodwin, P. J., \& Chlebowski, R. T. (2016). Obesity and cancer: Insights for clinicians. Journal of Clinical Oncology, 34(35), 4197-4202. https:// doi.org/10.1200/JCO.2016.70.5327

Greenlee, H., Shi, Z., Molmenti, C. L. S., Rundle, A., \& Tsai, W. Y. (2016). Trends in obesity prevalence in adults with a history of cancer: Results from the US National Health Interview Survey, 1997 to 2014. Journal of Clinical Oncology, 34(26), 3133-3140. https://doi. org/10.1200/JCO.2016.66.4391

Hu, W.-H., Cajas-Monson, L. C., Eisenstein, S., Parry, L., Cosman, B., \& Ramamoorthy, S. (2015). Preoperative malnutrition assessments as predictors of postoperative mortality and morbidity in colorectal cancer: An analysis of ACS-NSQIP. Nutrition Journal, 14, 91. https:// doi.org/10.1186/s12937-015-0081-5

Jensen, B. T. J., Krintel Petersen, A. K. P., Jensen, J. B., Lausten, S. L., \& Borre, M. B. (2014). Efficacy of an exercise-based rehabilitation programme in radical cystectomy pathways: A randomised controlled trial. European Urology Supplements, 13, e219. https://doi. org/10.1016/s1569-9056(14)60216-5

Jensen, B. T., Petersen, A. K., Jensen, J. B., Laustsen, S., \& Borre, M. (2015). Efficacy of a multiprofessional rehabilitation programme in radical cystectomy pathways: A prospective randomized controlled trial. Scandinavian Journal of Urology, 49(2), 133-141. https://doi.org/ 10.3109/21681805.2014.967810

Jiralerspong, S., \& Goodwin, P. J. (2016). Obesity and breast cancer prognosis: Evidence, challenges, and opportunities. Journal of Clinical Oncology, 34(35), 4203-4216.

Jones, L. W., Peddle, C. J., Eves, N. D., Haykowsky, M. J., Courneya, K. S., Mackey, J. R., ... Reiman, T. (2007). Effects of presurgical exercise training on cardiorespiratory fitness among patients undergoing thoracic surgery for malignant lung lesions. Cancer, 110(3), 590-598. https://doi.org/10.1002/cncr.22830

Land, L. H., Dalton, S. O., Jensen, M.-B., \& Ewertz, M. (2012a). Impact of comorbidity on mortality: A cohort study of 62,591 Danish women diagnosed with early breast cancer, 1990-2008. Breast Cancer Research and Treatment, 131(3), 1013-1020.

Land, L. H., Dalton, S. O., Jensen, M. B., \& Ewertz, M. (2012b). Influence of comorbidity on the effect of adjuvant treatment and age in patients with early-stage breast cancer. British Journal of Cancer, 107(11), 1901-1907. https://doi.org/10.1007/s10549-011-1819-1

Le Roy, B., Pereira, B., Bouteloup, C., Costes, F., Richard, R., Selvy, M., ... Pezet, D. (2016). Effect of prehabilitation in gastro-oesophageal adenocarcinoma: Study protocol of a multicentric, randomised, control trial-the PREHAB study. British Medical Journal Open, 6(12), e012876.

Li, C., Carli, F., Lee, L., Charlebois, P., Stein, B., Liberman, A. S., ... Feldman, L. S. (2013). Impact of a trimodal prehabilitation program on functional recovery after colorectal cancer surgery: A pilot study. Surgical Endoscopy, 27(4), 1072-1082. https://doi.org/10.1007/ s00464-012-2560-5

Macmillan Cancer Support (2018). Cancer rehabilitation pathways. London, UK: Macmillan Cancer Support.

Mayo, N., Feldman, L., Scott, S., Zavorsky, G., Kim, D., Charlebois, P., ... Carli, F. (2011). Impact of preoperative change in physical function on postoperative recovery: Argument supporting prehabilitation for colorectal surgery. Surgery, 150(3), 505-514. https://doi. org/10.1016/j.surg.2011.07.045

Minnella, E. M., Awasthi, R., Gillis, C., Fiore, J. F. Jr, Liberman, A. S., Charlebois, P., ... Carli, F. (2016). Patients with poor baseline walking capacity are most likely to improve their functional status with multimodal prehabilitation. Surgery, 160(4), 1070-1079. https://doi. org/10.1016/j.surg.2016.05.036

Montgomery, A. A., Peters, T. J., \& Little, P. (2003). Design, analysis and presentation of factorial randomised controlled trials. BMC Medical Research Methodology, 3(1), 26. https://doi. org/10.1186/1471-2288-3-26 
Moriya, T. (2015). Effects of preoperative use of an immune-enhancing diet on postoperative complications and long-term outcome: A randomized clinical trial in colorectal cancer surgery in Japanese patients. Gastroenterology and Hepatology, 2(1), 1-8.

National Academies of Sciences, E.a.M. (2018). Long-term survivorship care after cancer treatment: Proceedings of a workshop. Washington, DC, USA: The National Academies Press.

Onstad, M. A., Schmandt, R. E., \& Lu, K. H. (2016). Addressing the role of obesity in endometrial cancer risk, prevention, and treatment. Journal of Clinical Oncology, 34(35), 4225-4230. https://doi.org/10.1200/ jco.2016.69.4638

Parker, P. A., Pettaway, C. A., Babaian, R. J., Pisters, L. L., Miles, B., Fortier, A., ... Cohen, L. (2009). The effects of a presurgical stress management intervention for men with prostate cancer undergoing radical prostatectomy. Journal of Clinical Oncology, 27(19), 3169-3176. https://doi.org/10.1200/jco.2007.16.0036

Peddle, C. J., Jones, L. W., Eves, N. D., Reiman, T., Sellar, C. M., Winton, T., \& Courneya, K. S. (2009). Effects of presurgical exercise training on quality of life in patients undergoing lung resection for suspected malignancy: A pilot study. Cancer Nursing, 32(2), 158-165.

Sarfati, D., Koczwara, B., \& Jackson, C. (2016). The impact of comorbidity on cancer and its treatment. CA: A Cancer Journal for Clinicians, 66, 337-350 (1542-4863 (Electronic)). https://doi.org/10.3322/ caac. 21342

Schmid, D., \& Leitzmann, F. (2014). Association between physical activity and mortality among breast cancer and colorectal survivors: A systematic review and meta-analysis. Annals of Oncology, 25, 12931311. https://doi.org/10.1093/annonc/mdu012

Schmidt, M., Eckardt, R., Scholtz, K., Neuner, B., vonDossow-Hanfstingl, V., Sehouli, J., ... P. (2015). Patient empowerment improved perioperative quality of care in cancer patients aged $\geq 65$ years - a randomized controlled trial. PLoS ONE, 10(9), e0137824. https://doi.org/10.1371/ journal.pone.0137824

Schmitz, K. H., Courneya, K. S., Matthews, C., Demark-Wahnefried, W., Galvão, D. A., Pinto, B. M. ... Medicine, m.C.o.S. (2010). American college of sports medicine roundtable on exercise guidelines for cancer survivors. Medicine and Science in Sports and Exercise, 42, 1409-1426. https://doi.org/10.1249/MSS.0b013e3181e0c112

Sekine, Y., Chiyo, M., Iwata, T., Yasufuku, K., Furukawa, S., Amada, Y., ... Fujisawa, T. (2005). Perioperative rehabilitation and physiotherapy for lung cancer patients with chronic obstructive pulmonary disease. Japanese Journal of Thoracic and Cardiovascular Surgery, 53(5), 237-243.

Shamseer, L., Moher, D., Clarke, M., Ghersi, D., Liberati, A., Petticrew, M., ... Group, t.P.-P. (2015). Preferred reporting items for systematic review and meta-analysis protocols (PRISMA-P) 2015: Elaboration and explanation. BMJ, 349, g7647.

Shun, S. C. (2016). Cancer prehabilitation for patients starting from active treatment to surveillance. Asia-Pacific Journal of Oncology Nursing, 3(1), 37-40.

Silver, J. K. (2014). Cancer rehabilitation and prehabilitation may reduce disability and early retirement. Cancer, 120(14), 2072-2076. https:// doi.org/10.1002/cncr.28713

Silver, J. K. (2015). Cancer prehabilitation and its role in improving health outcomes and reducing health care costs. Seminars in Oncology Nursing, 31(1), 13-30. https://doi.org/10.1016/j.soncn.2014.11.003

Silver, J. K., \& Baima, J. (2013). Cancer prehabilitation: An opportunity to decrease treatment-related morbidity, increase cancer treatment options, and improve physical and psychological health outcomes. American Journal of Physical Medicine \& Rehabilitation, 92(8), 715-727. https://doi.org/10.1097/PHM.0b013e31829b4afe

Singh, F., Netwon, R., Galvao, D., Spry, N., \& Baker, M. (2013). A systematic review of pre-surgical exercise intervention studies with cancer patients. Surgical Oncology, 22, 92-104. https://doi.org/10.1016/j. suronc.2013.01.004
Sitas, F., Webe, M., Egger, S., Yap, S., Chiew, M., \& O'Connell, D. (2014). Smoking cessation after cancer. Journal of Clinical Oncology, 32(32), 3593-3595. https://doi.org/10.1200/jco.2014.55.9666

Smith, S. R., Khanna, A., \& Wisotzky, E. M. (2017). An evolving role for cancer rehabilitation in the era of low-dose lung computed tomography screening. PM\&R, 9(9), S407-S414. https://doi.org/10.1016/j. pmrj.2017.06.005

Søgaard, M., Thomsen, R. W., Bossen, K. S., Sørensen, H. T., \& Nørgaard, M. (2013). The impact of comorbidity on cancer survival: A review. Clinical Epidemiology, 5(Suppl 1), 3-29. https://doi.org/10.2147/clep.s47150

Stacey, F. G., James, E. L., Chapman, K., Courneya, K. S., \& Lubans, D. R. (2015). A systematic review and meta-analysis of social cognitive theory-based physical activity and/or nutrition behavior change interventions for cancer survivors. Journal of Cancer Survivorship, 9(2), 305-338. https://doi.org/10.1007/s11764-014-0413-z

Stairmand, J., Signal, L., Sarfati, D., Jackson, C., Batten, L., Holdaway, M., \& Cunningham, C. (2015). Consideration of comorbidity in treatment decision making in multidisciplinary cancer team meetings: A systematic review. Annals of Oncology, 26, 1325-1332. https://doi. org/10.1093/annonc/mdv025

Stefanelli, F., Meoli, I., Cobuccio, R., Curcio, C., Amore, D., Casazza, D., ... Rocco, G. (2013). High-intensity training and cardiopulmonary exercise testing in patients with chronic obstructive pulmonary disease and nonsmall-cell lung cancer undergoing lobectomy. European Journal of CardioThoracic Surgery, 44(4), e260-265. https://doi.org/10.1093/ejcts/ezt375

Sterne, J. A., Hernán, M. A., Reeves, B. C., Savović, J., Berkman, N. D., Viswanathan, M., ... Higgins, J. P. (2016). ROBINS-I: A tool for assessing risk of bias in non-randomised studies of interventions. BMJ, 355. https://doi.org/10.1136/bmj.i4919

Stout, N. L., Alfano, C. M., Belter, C. W., Nitkin, R., Cernich, A., Lohmann Siegel, K., \& Chan, L. (2018). A bibliometric analysis of the landscape of cancer rehabilitation research (1992-2016). Journal of the National Cancer Institute, 110(8), 815-824. https://doi.org/10.1093/jnci/djy108

Stout, N. L., Silver, J. K., Raj, V. S., Rowland, J., Gerber, L., Cheville, A., ... Chan, L. (2016). Toward a national initiative in cancer rehabilitation: Recommendations From a subject matter expert group. Archives of Physical Medicine and Rehabilitation, 97(11), 2006-2015. https://doi. org/10.1016/j.apmr.2016.05.002

Sueppel, C., Kreder, K., \& See, W. (2001). Improved continence outcomes with preoperative pelvic floor muscle strengthening exercises. Urologic Nursing, 21(3), 201-210.

Thompson, W., Gordon, N., \& Pescatello, L. (2010). ACSM's guildeines for exercise testing and prescription. Philadelphia, PA, USA: Lippincott, Williams and Wilkins.

Tsimopoulou, I., Pasquali, S., Howard, R., Desai, A., Gourevitch, D., Tolosa, I., \& Vohra, R. (2015). Psychological prehabilitation before cancer surgery: A systematic review. Annals of Surgical Oncology, 22(13), 4117-4123. https://doi.org/10.1245/s10434-015-4550-z

Van Bokhorst-de Van der Schuer, M. A., Langendoen, S. I., Vondeling, H., Kuik, D. J., Quak, J. J., \& Van Leeuwen, P. A. (2000). Perioperative enteral nutrition and quality of life of severely malnourished head and neck cancer patients: A randomized clinical trial. Clinical Nutrition, 19(6), 437-444.

Vidal, A., Howard, L., Moreira, D., Castro-Santamaria, R., Andriole, G. L., \& Freedland, S. J. (2014). Obesity increases the risk for highgrade prostate cancer: Results from the REDUCE study. Cancer Epidemiology, Biomarkers \& Prevention, 23(12), 2936-2942. https:// doi.org/10.1158/1055-9965

Warren, G. W., Sobus, S., \& Gritz, E. R. (2014). The biological and clinical effects of smoking by patients with cancer and strategies to implement evidence-based tobacco cessation support. The Lancet. Oncology, 15(12), e568-e580. https://doi.org/10.1016/S1470-2045(14)70266-9

West, M. A., Loughney, L., Lythgoe, D., Barben, C. P., Sripadam, R., Kemp, G. J., ... Jack, S. (2015). Effect of prehabilitation on objectively measured physical fitness after neoadjuvant treatment in preoperative 
rectal cancer patients: A blinded interventional pilot study. British Journal of Anaesthesia, 114(2), 244-251. https://doi.org/10.1093/ bja/aeu318

Winters-Stone, K., Dieckmann, N., Maddalozzo, G., Bennett, J. A., Ryan, C. W., \& Beer, T. M. (2015). Resistance exercise reduces body fat and insulin during androgen-deprivation therapy for prostate cancer. Oncology Nursing Forum, 42(4), 348-356.

Yang, L., Drake, B. F., \& Colditz, G. A. (2016). Obesity and other cancers. Journal of Clinical Oncology, 34(35), 4231-4237. https://doi. org/10.1200/jco.2016.68.4837
How to cite this article: Faithfull S, Turner L, Poole K, et al. Prehabilitation for adults diagnosed with cancer: A systematic review of long-term physical function, nutrition and patient-reported outcomes. Eur J Cancer Care. 2019;e13023. https://doi.org/10.1111/ecc.13023 